\title{
Tracing risky decisions for oneself and others: The role of intuition and deliberation
}

Kinga Posadzy and Jan Hausfeld

The self-archived postprint version of this journal article is available at Linköping University Institutional Repository (DiVA):

http://urn.kb.se/resolve?urn=urn:nbn:se:liu:diva-160742

N.B.: When citing this work, cite the original publication.

Posadzy, K., Hausfeld, J., (2019), Tracing risky decisions for oneself and others: The role of intuition and deliberation, Journal of Economic Psychology. https://doi.org/10.1016/j.joep.2019.102188

Original publication available at:

https://doi.org/10.1016/j.joep.2019.102188

Copyright: Elsevier

http://www.elsevier.com/

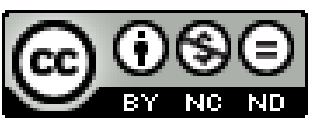




\title{
Tracing Risky Decisions for Oneself and Others: The Role of Intuition and Deliberation
}

\author{
Kinga Barrafrem ${ }^{1}$, Jan Hausfeld ${ }^{2}$
}

This study contributes to the understanding of how individuals make choices for themselves and on behalf of others in a risky environment. We investigate whether decisions and information processing differ between decisions made for oneself and on behalf of others. Further, we test whether cognitive processing can explain differences in decisions for oneself and other individuals. To this end, we experimentally induce an intuitive or a deliberative processing type. In a laboratory eye-tracking experiment, we investigate risk preferences, decision error, and information processing. While we find no differences in risk preferences when deciding for oneself or for someone else, individuals have a greater decision error when deciding for others. Process data partly explains these differences. Individuals spend less time, have less fixations, and inspect less information when deciding for others. We detect similar processing patterns when comparing intuitive and deliberative decision making. We argue that the processing of decisions for oneself is more effortful and involves more extensive deliberation which, in turn, is related to less decision errors.

JEL codes: C91, D81

Keywords: decision making for others, risk preferences, decision noise, dual-process theory, eye-tracking

\footnotetext{
1 Corresponding author, Linköping University, Department of Management and Engineering, Division of Economics, 58183 Linköping, Sweden; kinga.barrafrem@liu.se.

${ }^{2}$ University of Konstanz, Department of Economics, Graduate School of Decisions Sciences; Thurgau Institute of Economics; University of Bern, Department of Psychology, jan.hausfeld@uni-konstanz.de
} 


\section{Introduction}

Have you ever invested in stocks of a company that simply "feels right" and that you like without doing the diligent examination of its profitability, or the growth potential? Would you make the same decision if you were to invest for another person? The examples of situations in which individuals decide for other people are abundant and range from mundane decisions, e.g., which lunch to order for a friend who is running late, to more serious ones, such as medical doctors deciding whether to perform a surgery or not. Deciding on behalf of other people may involve different decision processes than those that are present during the decision-making process for oneself. In this study, we investigate whether individuals decide for others in the same way as they decide for themselves and how this decision process relates to their choices as well as the decision noise (i.e., error in the decision representing inconsistent decisionmaking).

Decisions can be seen as a result of an interplay between deliberative, analytical processing and intuitive, experiential, emotionally-based processing (dual-process theory, see for example, Epstein 1994). When comparing choices, on the one hand, it is possible that people simply integrate all information available and make a calculated decision involving deliberative processing regardless of who is affected by the choice. On the other hand, the very same information might evoke emotions, such as fear of losing or excitement about a potential win, when deciding for oneself. Plausibly, these emotions are not as strong when deciding for another person. Similarly, Mengarelli et al. (2014) suggest that the self-other discrepancies in risky decisions stem from the differences in real and emotional consequences of decisions. Stronger emotional involvement can lead to a greater influence of intuitive processes when deciding for oneself in comparison to deciding for others.

The explanations for the self-other gap derived from the dual-process theory can be juxtaposed with economic theory. The idea that both intuitive and deliberative processes influence decisions to various degrees is inconsistent with economic theory. In fact, decisions made by economic agents are assumed to be calculated, rational, utility maximizing, and hence, based on deliberation. There is no room for intuition. Nonetheless, the assumption of perfectly rational economic agent has been questioned on multiple occasions. A wide range of behavioral studies suggest that individuals have bounded rationality due to, amongst other things, limited cognitive capacities (Simon 1959; Becker 1962; Thaler 1980). Thus, deliberation is not 
effortless (Conlisk 1996), but requires both time and cognitive resources. ${ }^{1}$ Given these limitations, utility maximizing agents have to choose the amount of effort exerted when making choices. This effort will be higher, the higher the perceived benefits (utility gains) are. Arguably, the perceived benefits are higher when an individual decides for herself than for another person, as the consequences of her choices will directly affect her monetary payoff. This might result in more cognitive processing when deciding for oneself than when deciding on behalf of others.

The objective of this study is to examine how decisions, decision error, and information processing differ when deciding for oneself and on behalf of another person in a risky environment. We juxtapose the predictions based on the dual-process theory with the predictions based on the utility maximizing approach. The first one assumes greater influence of intuitive processes on decisions for oneself in comparison to decisions for others and the latter one assumes more extensive deliberation when deciding for oneself.

We conduct an eye-tracking experiment in which every subject makes lottery choices that directly affect her payoff (Self) as well as choices that affect only the payoff of another anonymous person (Other). We use eye-trackers to record information processing in the lottery task. The processing data provides better insights into the decision-making process which improves our understanding of not only whether but also why there are differences in choices between self and others. We manipulate processing types in three treatments (deliberation, intuition, control) in a between-subject design using implementation intentions (Gollwitzer 1999). While we are primarily interested in the comparison of behavior and information processing between Self and Other choices, we manipulate processing types to establish what behavioral and processing patterns are characteristic for more intuitive processing and what patterns are characteristic for more deliberative processing. This way, we can infer how different processing types affect information processing and avoid the reverse inference trap of reasoning backwards, i.e., using response time as evidence for dual-process theories (Krajbich et al. 2015). We analyze individuals' behavior by estimating risk preferences and decision error using structural estimations. These estimates are complemented with an analysis of information processing measures. To the best of our knowledge, there exists no eye-tracking study inspecting both processing and behavior in decision making for others.

The present work extends previous research on risky decision making for oneself and others by eliciting both risk preferences and decision error (noise). Although considerable

\footnotetext{
${ }^{1}$ Using cognitive resources has been assumed to be costly in previous studies, for example, in models integrating dual processes into drift diffusion models (Alós-Ferrer 2018; Caplin and Martin 2016).
} 
research has been devoted to exploring self-other differences in risk preferences, little attention has been paid to decision noise. However, it can have grave consequences for decision makers and businesses; recently, Kahneman et al. (2016) emphasized the extremely high costs of noise in the organizations reaching billions of dollars and the urgency of reducing the inconsistency of decisions. Our results show that decision noise is greater when making decisions for others, indicating potential problems of delegated decision making. In addition, we find no differences in risk preferences when comparing decisions for oneself and for others. This study also contributes to the current understanding of how decisions for oneself and for others are made using eye-tracking. We show that individuals employ significantly less cognitive processing when deciding for other people. This is consistent with the assumption that cognitive effort is costly and utility maximizing agents reduce effort if there is no personal gain from it. Further, our study contributes to the discussion on the effect of processing mode on decision making. We find that individuals are more loss averse and less sensitive to mid-range probabilities in deliberation treatment than in control or intuition treatments. Lastly, we compare self-other decision processes to deliberation-intuition processes: we find that deciding for oneself resembles a more deliberative decision process relative to deciding for someone else.

We review the relevant literature in section II and derive two sets of hypotheses. In section III, we describe the experiment, eye-tracking measurements, and estimation methods. Results are presented in section IV. We first look at risk behavior and processing data separately. Then, we use structural estimation model to relate the eye-tracking data to risk behavior. We conclude and discuss the study in section V.

\section{Literature review}

Up to date, studies comparing decision making for oneself and others mostly relied on behavioral data. ${ }^{2}$ The results are inconclusive. Some studies show decreased risk aversion when deciding for strangers (e.g. Chakravarty et al. 2011; Pollmann et al. 2014). Similarly, Mengarelli et al. (2014) show that individuals are not only more risk averse but also more loss averse when deciding for themselves compared to when deciding on behalf of others. Greater loss aversion when deciding for oneself (but no differences in risk taking) has been found, amongst others, by Andersson et al. (2016a), Füllbrunn and Luhan (2017), and Polman (2012). On the contrary, studies that involve lower levels of anonymity show that individuals are more

\footnotetext{
${ }^{2}$ In this study, we only compare decisions made for oneself with decisions made for another person without affecting the decision maker. Thus, we do not discuss studies that investigate how decision-making changes when others as well as the decision maker are affected by it, due to the differences in incentives for the decision maker (e.g., Pahlke et al. 2012; Pahlke et al. 2015; Bolton et al. 2015; Leder and Betsch 2016).
} 
risk averse with other people's money (e.g., Eriksen and Kvaløy 2010; Reynolds et al. 2011). Finally, Jung et al. (2013) show that self-other differences in risk-aversion depend on the probability of winning. If the probability is high, individuals are more risk seeking with their own money than others' money, but if the probability of winning is low, they are more risk averse with their own money than others' money.

Liu et al. (2018) analyze how much information individuals gather when they decide either for themselves or for a close friend. In their study subjects can choose whether they want to see (or buy) more pieces of information. The authors find that subjects deciding for other people, search through more information even though there are no self-other differences in decision time.

Lu et al. (2016) investigate inaction inertia when choosing for oneself or a friend in an experimental setting using eye-tracking. In one of the experiments, subjects decided whether to buy a discounted product, knowing that the discount was greater in the past. They find that subjects exhibited less inaction inertia when deciding for a friend. Furthermore, when deciding for oneself, subjects had more fixations on previous price than original price, while there was no difference in fixations on prices for individuals deciding for their friends. This suggests higher sensitivity for gains when deciding for a friend.

\section{A. Dual-process theories}

Previous research does not identify one specific mechanism responsible for the differences in choices between decisions for oneself and on behalf of others. In this study, we consider dual-process theory as a potential channel for the self-other decision differences. Dualprocess theories posit that there are two parallel types of cognitive processing that interact with each other: intuitive processes and deliberative processes (see for example Epstein 1994, Sloman 1996, Kahneman 2003). Intuitive choices are frequently fast and frugal, affect-laden, require low cognitive effort, and are based on past experiences. Often, subjects who rely on intuitive processes use simple rules of thumb that do not require processing of all information. On the other hand, deliberative choices are usually slower, more thought-through, rational, require high cognitive effort, and are based on logical analysis (see Alós-Ferrer and Strack 2014 , for an overview of dual-process theories).

Emotions have been shown to have a significant impact on decisions (see for example, Loewenstein 2000; Rick and Loewenstein 2008). For instance, when making decisions under uncertainty, individuals might fear negative outcomes and hence choose a safer option (see risk- 
as-feelings hypothesis, Loewenstein 2001). The affect heuristic posits that the affect experienced at the moment of decision making, i.e., the feeling of "right" or "wrong", can cloud cognitive capacities and lead to decisions based on intuitive processes (Slovic et al. 2002). Presumably, emotions play a more significant role when individuals are directly affected by the consequences of their decisions (e.g., when deciding for oneself) in comparison to when they are not directly affected (e.g., when deciding for a stranger). This is consistent with Jung et al. (2013) who propose that stronger affect experienced when deciding for oneself may override cognitive processing which leads to decisions relying on the intuitive responses to tasks rather than on calculations. In line with this, we hypothesize that choices for oneself are more emotionally charged than choices for others, whereby emotions cloud cognitive capacities, and thus decisions for oneself resemble more intuitive choices. These emotions are not as strong when deciding for others. Thus, deciding for others can trigger more deliberative processes. In other words, the dual-processes hypothesis predicts similar decision and processing patterns in Self condition as in intuition treatment and in Other condition as in deliberation treatment.

Hsee and Rottenstreich (2004) show that as the reliance on emotions in the evaluation of outcomes increases, the decisions display greater risk seeking in the loss domain and greater risk aversion in the gain domain. Further, Rottenstreich and Hsee (2001) show that increased affect leads to greater probabilistic insensitivity. This suggests that affective choices are further from risk neutrality than deliberative choices. This line of reasoning leads us to hypothesize that when deciding for others, individuals will make choices that are closer to risk neutrality. Furthermore, in line with Kirchler et al. (2017) who show that more intuitive choices increase the noise in decision making, we hypothesize that the decision error in Self condition is greater than in Other condition.

Horstmann et al. (2009) show that individuals instructed to deliberate conduct a more thorough and repeated information search, i.e., they collect more information as well as inspect the same information more frequently. However, they do not find differences regarding the duration of a fixation on a single item. Thus, if choices for oneself are more intuitive than choices made for others, individuals will decide faster as well as inspect and process less information when deciding for oneself than for others.

\section{B. Utility maximization}

The self-other decision gap found in previous studies can also result from differences in incentives when deciding for oneself and when deciding for someone else. Economic agents are utility maximizers, i.e., their decisions result from a cost-benefit analysis in which potential 
rewards of each available option are weighed against anticipated costs. The same should hold when it comes to cognitive effort. Cognitive effort is a scarce resource due to limited information processing and cognitive capacities (Simon 1955), and thus the use of cognitive effort should be optimized when making decisions (Kool et al. 2010). While investing cognitive effort in deciding is believed to move individuals' decisions closer to theoretical optimum and reduce decision error, it is costly (Smith and Walker 1993). Thus, in the course of decisionmaking process, individuals need to trade-off the cost of cognitive effort for the accuracy benefits of more extensive deliberation. In this sense, exerting little effort might turn out rational if the cognitive costs are high or potential benefits inadequately low (Hausfeld and Resnjanskij 2017).

Greater incentives usually increase attention to information or foster deliberation, which may or may not lead to better decisions (Tversky and Kahneman 1986). Camerer and Hogarth (1999) and Hertwig and Ortmann (2001) find that incentives can improve performance only in some cases, while in others they either have no or negative impact on performance. While cognitive effort, does not necessarily translate to better performance, it does improve the quality of decisions by reducing decision noise (Smith and Walker 1993; Camerer and Hogarth 1999; Hertwig and Ortmann 2001). This is also in accordance with Andersson et al. (2016b) who find that higher cognitive ability is related to lower decision error. In line with these findings we hypothesize that if individuals derive lower utility from the payoffs of others than their own payoffs, they will exert less cognitive effort on the choices made for others resulting in lower consistency of these choices. ${ }^{3}$ This means higher decision errors when deciding for others than when deciding for oneself. Given that information collection and cognitive reasoning are costly, individuals will spend less time, have less and shorter fixations, and inspect less information when deciding on behalf of others in comparison with when deciding for themselves.

\section{Eye-tracking}

While traditional economic experiments deliver important knowledge about the outcomes and consequences of individuals' decisions, they usually do not provide evidence for underlying decision processes. However, studying the mechanisms behind the decision making enables researchers to better understand individuals' behavior. As emphasized by Simon (1955), people have bounded rationality and their limited cognitive capacities and information processing constraints may lead them to decisions that diverge from rationality.

\footnotetext{
${ }^{3}$ This hypothesis makes no predictions about risk preferences.
} 
The urge to understand behavioral processes has encouraged researchers to complement their studies with methods such as eye-tracking, functional Magnetic Resonance Imaging (fMRI), and galvanic skin response, to name a few, that give insights into information processing (Sickmann and Le 2016). Eye-tracking is recognized as a relatively non-invasive and fairly accurate method that can be applied in experimental studies at a relatively low-cost. Eye-tracking allows researchers to record gaze of participants making choices. Given that eye fixation and information processing happen simultaneously, the data collected by eye-trackers helps to understand processing of the decisions (Orquin and Mueller Loose 2013).

Recently, several researchers have made attempt to review the growing number of studies using eye-tracking in economics and psychology (for example, Orquin and Mueller Loose 2013, Fiedler and Glöckner 2015, Sickmann and Le 2016). Previous studies have focused on the prediction of choices based on the gaze patterns (see for example, Shimojo et al. 2003, Krajbich et al. 2010). It has been shown that individuals tend to look more at options they are more likely to choose (see Stewart et al. 2016 and Fiedler and Glöckner 2012 for findings in risky decision-making, Reutskaja et al. 2011 for findings in shopping behavior, and Ghaffari and Fiedler 2018 for findings in the social context). In addition, eye-tracking has been used to test existing theories and develop new models. For instance, Stewart et al. (2016) test existing process models of risky decision making (e.g., using heuristics, predictions of decision field theory, etc.) and find that these models predict more complicated processing than what actually takes place: people choose the gamble they look at most frequently. Eye-tacking has also been used outside of the risky decision-making context to look at the processes, for example, in strategic decisions (Wang et al. 2010; Polonio et al. 2015; Devetag et al. 2016), moral and social decisions (Fiedler et al. 2013; Jiang et al. 2016), and lying (Wang et al. 2010; Hochman et al. 2016).

\section{Methods}

We conducted an eye-tracking lab experiment with 128 participants recruited via ORSEE (Greiner 2015) at Lakelab, the economic experiments laboratory at the University of Konstanz. The experiment was programmed in z-Tree (Fischbacher 2007). Sessions lasted between 75 and 90 minutes. The outline of our experiment is presented in Figure 1. Individuals first completed the social value orientation survey (SVO, Murphy et al. 2011), then we manipulated the decision processing mode. We conducted two blocks of an incentivized lottery task intercepted with a manipulation reminder. The experiment ended with a short investment task aiming to elicit beliefs about relative risk preferences, and a questionnaire. In this study we 
focus on the analysis of risk preferences, i.e., in our data analysis we use data from the lottery task. We discuss the robustness of our results with respect to beliefs, social value orientation, and empathy in Appendix C.

Figure 1: The experiment outline. Choice data was collected for all but manipulation stages. Eye-tracking data was collected for Block 1 lotttery task.

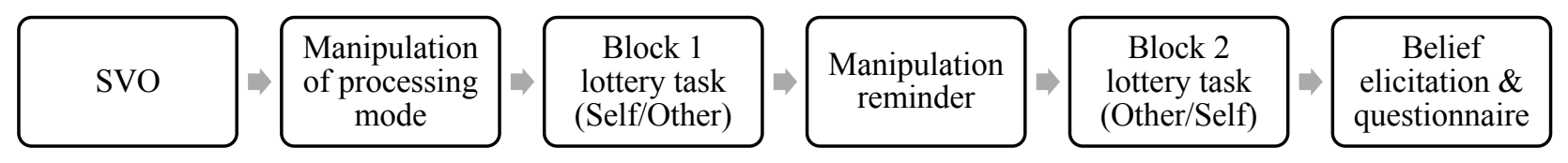

\section{A. Experimental design}

We utilized a 3 × 2 mixed factorial design. We had three between-subject treatments, namely control, deliberation and intuition, which differed in the manipulation of the processing mode. In addition, in the lottery task, every subject made 45 lottery choices for themselves (Self) and 45 lottery choices for another person (Other). Subjects were informed that both they and the other person remain anonymous, and that the person they were choosing for did not make choices for them. Subjects learned about the Self and Other conditions after they read the instructions, answered the control questions, and completed the manipulation task. The order of Self and Other conditions was randomized.

We manipulated the processing type using directly instructed implementation intentions (see Gollwitzer 1999; Halberstadt and Levine 1999). The manipulation worked as follows: first, subjects received written instructions about what we were interested in (i.e., investigating the benefits of relying on intuition/careful consideration), what were the obstacles in achieving the goal (contemplating/acting hastily) and how to circumvent them, followed by the introduction of so-called if-then plans ("If I start [pondering at length / acting in a hasty way], then I will tell myself: [Listen to your guts / Use your brain]!"). ${ }^{4}$ Subjects were asked to read their if-then plan in their minds several times, to remember it, and to write it down. Subjects were reminded about their if-then plans before the second block (Self or Other). Implementation intentions enable people to make mental plans that prepare them when they encounter an obstacle to achieve a specific goal. Implementation intentions have been shown to have positive effect on the achievement of wide variety of goals (Gollwitzer and Sheeran 2006). The if-then plans used in our experiment were based on Bieleke et al. (2017) who applied them to successfully induce

\footnotetext{
${ }^{4}$ The instructions for the different manipulations and the lottery task can be found in the Appendix F-J.
} 
intuitive versus deliberative modes of processing. The processing type was not manipulated in the control treatment.

\section{B. Experimental Protocol}

In the lottery task, subjects were presented with 90 three-outcome lottery pairs which were split randomly into two blocks of 45 decisions either made for oneself (Self) or on behalf of another person (Other). The lotteries were selectively adopted from Hey and Orme (1994). Similar gambles have been used in other studies (e.g., Harrison and Rutström 2008). ${ }^{5}$ This type of lotteries provides a rich dataset for structural estimations. Each block included 15 lottery pairs involving only positive outcomes (gain), 15 lottery pairs involving only negative outcomes (loss), and 15 lottery pairs involving both positive and negative outcomes (mixed). The order of gain, loss, and mixed lotteries was randomly determined for each subject, as well as which option was presented on the left or right side of the screen. For each decision, both lottery options yielded the same potential outcomes, but differed in the probability distributions. The possible outcomes in the gain domain were fixed at four levels: $0,5,10$ or 15 points. In the mixed domain, the values were either $-8,-3,3$ or 8 points and subjects received an endowment of 8 points before this part. The possible outcomes in the loss domain were fixed at four levels: $0,-5,-10$ or -15 points. Before the part with loss lotteries, subjects received an endowment of 15 points. ${ }^{6}$ Thus, all lotteries had roughly equal final outcomes when accounting for the endowment. The probabilities ranged from $0 \%$ to $100 \%$ in steps of 12.5 percentage points. The screen position of the values and probabilities were counterbalanced across subjects in order to avoid biases in information processing. Subjects chose either left or right lottery by pressing a button on the keyboard. Before each choice, a fixation cross appeared for one second in the middle of the screen. Each point in this task was worth $€ 0.5$.

Before the lottery task, individuals completed social value orientation survey (SVO, Murphy et al. 2011). After the lottery task, subjects were presented with an incentivized task that measured their beliefs about relative risk taking of the other person. Lastly, subjects were

\footnotetext{
${ }^{5}$ We tested different sets of lotteries in an online pilot study and three further lab pilots. We adjusted the number and the choice of specific lotteries after the analysis of pilot data.

${ }^{6}$ Real losses present an ethical issue. Giving initial endowment to subjects ensured that no subject lost her own money which is against the rule of the lab in which experiment was conducted. This method has also been widely used in previous studies, e.g., Harrison and Rutström (2008). Some researchers argue that initial endowment may create house-money effect (Thaler and Johnson 1990), however it can also serve as a reference point below which subjects incur losses. Etchart-Vincent and l'Haridon (2011) compare risk taking under different incentives: real loss incentives, losses from initial endowment, and no incentives and find no differences in risk behavior for loss lotteries suggesting that behavior in our study can be generalized to behavior when real losses are present.
} 
asked to fill in a questionnaire including measures of empathy and perspective taking (Davis 1980 ) and the preference for intuition and deliberation (PID scale, Betsch 2004). ${ }^{7}$ The latter one was implemented to test whether personal preferences for intuitive or deliberative processing differed between treatments. ${ }^{8}$ Subjects who were not in the control treatment also received five questions from the goal commitment questionnaire (Klein et al. 2001) to test if the commitment to the induced type of processing differed across treatments.

The payoffs consisted of $€ 5$ show-up fee, one lottery decision made by oneself, one lottery decision made by someone else, one paid out decision from the SVO, and the investment task. ${ }^{9}$ Subjects earned on average $€ 20$.

\section{Eye-Tracking}

The eye-tracking data was recorded using the stationary tracker Eye-Tribe, with a sampling rate of $60 \mathrm{~Hz}$, and the python module PyGaze (Dalmaijer et al. 2014). Subjects were placed in a chin rest with a distance to the screen of $58 \mathrm{~cm}$. We only use gaze data recorded during the lottery task. Figure E1 in Appendix presents one of the lottery choices. Due to a technical error caused by lagged recording, we do not have complete process data for the second block of the lottery task. Therefore, we only use the first block in eye-tracking data analysis. This implies that we cannot do within-subject self-other comparisons in the analysis of information processing. Thus, when analyzing processing data we conduct between-subject comparisons using 45 decisions in Block 1 lottery task (see Figure 1).

Each session consisted of 12 subjects being eye-tracked. A calibration was accepted if the error was less than $0.9^{\circ}$ of visual angle according to the delivered accuracy (mean: $0.3^{\circ}$ ). We defined a fixation using a dispersion-based algorithm as explained by Salvucci and Goldberg (2000). Following Salvucci and Goldberg (2000), we identified fixations using a maximum 30-pixel threshold for both $\mathrm{x}$ and y coordinates (which corresponds to around $1^{\circ}$ of

\footnotetext{
${ }^{7}$ See Appendix C for description of SVO task, belief elicitation and empathy task.

${ }^{8}$ The alternative scale used to measure cognitive styles is Rational Experiential Inventory (REI) which comprises two independent constructs: Faith in Intuition and Need for Cognition (Pacini and Epstein 1999). Both PID and REI have two-factor structure and have been repeatedly shown as reliable (see e.g., Witteman et al. 2009). While the REI scale or its components have been more frequently used in previous research (see e.g., Alós-Ferrer and Hügelschäfer 2012, 2016), we chose the shorter scale, PID, given that our experiment was already extensive.

${ }^{9}$ We used the incentive-compatible random-lottery payment scheme to eliminate wealth and portfolio effects and avoid hedging. The critics against this payment scheme argue that it introduces another layer of risk as well as dilutes incentives. However, multiple previous studies have shown that behavior under pay-one does not significantly differ from the behavior under pay-all in pairwise lottery selection tasks (e.g., Starmer and Sugden 1991, Laury 2006, Azrieli et al. 2018). Further, Charness et al. (2016) suggest that pay-one incentives are empirically superior in studies using binary lottery choices in their paper discussing pay-one and pay-all incentive schemes.
} 
visual angle as recommended by Blignaut 2009) for at least $101 \mathrm{~ms}$ (similar to Jiang et al. 2016 and Devetag et al. 2016). We used circular areas of interest (AOIs) with a 90-pixel radius from the center of the boxes with outcomes and probabilities which resulted in 12 non-overlapping AOIs. To assure that the experiment could continue according to the planned schedule and other subjects did not have to wait, subjects with several issues during the calibration skipped the calibration. This left us with eye-tracking data for 94 subjects. ${ }^{10}$ The eye-tracking subsample did not differ significantly from the full sample (see Table D1 in Appendix for comparison).

\section{Analysis}

The analysis consists of two sections: risk behavior and information processing. In each section we first compare differences between Self and Other followed by comparison across treatments. We use a structural estimation approach to estimate subjects' risk preferences based on the lottery task. Both, the attitudes towards outcomes and the attitudes towards probabilities have been shown to be influenced by affect during decision making (Rottenstreich and Hsee 2001; Hsee and Rottenstreich 2004). To this end, we choose cumulative prospect theory (CPT) as a descriptive model of risk behavior. For the functional form we assume the most widely used power value function (1) as defined by Tversky and Kahneman (1992) and estimate the curvature of the function $(\mu)$ :

$$
v(x)=\left\{\begin{array}{cc}
x^{\mu} & \text { if } x \geq 0 \\
-\lambda(-x)^{\mu} & \text { if } x<0
\end{array}\right.
$$

We assume the same marginal sensitivity towards gains and losses. Wakker (2008) points out that the functions from the power family can fit data well in the domain of risk taking and they have many desired features while preserving tractability.

We further assume a one parameter $(\gamma)$ cumulative probability weighting function (2) as suggested by Prelec (1998):

$$
w(p)=\exp \left(-(-\ln (p))^{\gamma}\right)
$$

The choice of both power value function and Prelec's probability weighting function has been also suggested by Stott (2006). This combination of functions provides the best balance between fit and parsimony in a horse race of 256 combinations of different functional forms describing risky behavior.

We calculate the valuation of prospect (lottery) $\mathrm{P}$ as:

$$
V_{i}(P)=\omega_{i 1} v_{i}\left(x_{1}\right)+\omega_{i 2} v_{i}\left(x_{2}\right)+\omega_{\mathrm{i} 3} v_{i}\left(x_{3}\right)
$$

\footnotetext{
${ }^{10}$ See Appendix A for a more detailed description of the eye-tracking methods.
} 
where $v_{i}()$ is the value function and $\omega_{i n}$ is the decision weight such that: $\omega_{\mathrm{i} 3}=w\left(p_{3}\right), \omega_{\mathrm{i} 2}=$ $w\left(p_{2}+p_{3}\right)-w\left(p_{3}\right), \omega_{\mathrm{i} 1}=1-w\left(p_{2}+p_{3}\right)$, given that $x_{1}<x_{2}<x_{3}$.

Assuming that $V(L)$ is the valuation of the left prospect and $V(R)$ is the valuation of the right prospect, we can calculate the differences between these valuations by $\Delta V=V(L)-$ $V(R)$. This gives us the likelihood function:

$$
L= \begin{cases}\Phi \Delta V, & \text { if Left Lottery } \\ 1-\Phi \Delta V & \text { if Right Lottery }\end{cases}
$$

We use the Fechner error specification to allow subjects to make errors as described by Hey and Orme (1994). ${ }^{11}$ It implies that individuals make stochastic choices, rather than deterministic choices. Fechner error models the randomness factor that enters at the stage when individuals evaluate and compare the available options. We account for this type of decision error by adding a noise parameter to the difference between expected values of left and right lottery. The noise parameter is normally distributed with mean equal zero and standard deviation equal $\sigma$ (the estimated parameter).

Furthermore, the difference in valuation $\Delta V=V(L)-V(R)$ is standardized according to Wilcox (2011) to be bounded within the interval [-1, 1]. Wilcox standardization alleviates the nonmonotonicity problem in stochastic discrete choice models, in which the probability of choosing riskier lottery might be larger for larger levels of risk aversion. ${ }^{12}$

In order to analyze the cognitive processing, we inspect the following four measures: decision time, number of fixations, information inspection (the proportion of available information, i.e., areas of interest that have been inspected), as well as fixation duration. We compare the processing measures between the decisions for oneself and another person as well as between treatments. We conclude the analysis by complementing the structural model with information processing data.

In what follows, we use non-parametric Wilcoxon rank sum tests to test differences between two independent groups and Kruskall-Wallis tests to compare more than two groups. For the within-subject comparison, we use non-parametric Wilcoxon signed rank tests. All tests are two-tailed and the significance level used is 5\%. Given our sample size of 128 , we can detect a small-to-medium effect (Cohen's $\left.\mathrm{d}_{\mathrm{z}}=0.255\right)$ with power 0.8 in Wilcoxon signed rank

\footnotetext{
${ }^{11}$ The Fechner error specification has also been used by, e.g., Harrison et al. (2007); Bruhin et al. (2010); Caplin et al. (2011). Starmer (2000) provides a comprehensive review of different error specifications.

12 The problem of nonmonotonicity in the Random Utility Models has been further studied by Apesteguia and Ballester (2018), who also suggest a more general solution, Random Parameter Model (RPM). In RPM, the random error distorts the preference parameter, rather than the utility evaluation of each alternative independently preventing from monotonicity violation.
} 
tests on matched pairs. Further, for the eye-tracking subsample of 94, we can detect medium effects (Cohen's d=0.599) with power 0.8 in between-subject Wilcoxon rank sum tests. In structural estimations we use roughly 11500 observations which is considered a large sample.

\section{Results}

In total, 128 subjects participated in one of three treatments: 42 in control, 43 in deliberation, and 43 in intuition. We collected behavioral data for 90 decisions of every participant. ${ }^{13}$ As mentioned in section III.C, the processing data is analyzed for 94 subjects from the first block: 32 in control (18 Self condition and 14 Other condition), 32 in deliberation (16 Self condition and 16 Other condition), and 30 in intuition (10 Self condition and 20 Other condition). We start the analysis by checking whether subjects differed across treatments with respect to the preference for intuition and deliberation measured by the PID scale (Betsch 2004). We fail to reject the hypothesis that the deliberation and intuition scores are equal across treatments for any of the pairwise comparisons and for all treatments simultaneously. We also test whether goal attainment (Klein et al. 2001) differs between the induced plans and find no significant differences in committing to goals between subjects in the intuition and deliberation treatments.

Descriptive statistics of our sample and the eye-tracking subsample are presented in Table D1 in Appendix. The average age in our sample is 21.8 years, $62 \%$ of participants are females. We conduct $\chi^{2}$ tests and Wilcoxon rank sum tests for the eye-tracking subsample to test whether characteristics of the subjects for which we have processing data and of the subjects for which we do not have processing data differ, and find no statistically significant differences except for females, who are slightly overrepresented in the subsample of subjects who failed calibration.

\section{A. Risk behavior}

We begin the analysis by comparing the choices for Self and Other in the context of expected value maximization, i.e., the simplest normative model that does not require transformation of outcomes or probabilities and assumes risk neutrality. As can be seen in Figure 2, individuals are more likely to choose the option maximizing expected value when

\footnotetext{
${ }^{13}$ Due to one incorrectly displayed lottery in two sessions, the total number of observations used in analysis was reduced from 11520 to 11498 .
} 
deciding for themselves than when deciding for the other person $(p=0.037$, pooled across treatments).

Figure 2: Proportion of choices maximizing expected value by treatment for Self and Other $(\mathrm{n}=128)$. Error bars indicate the $95 \%$ confidence interval of the means accounting for the clustering at the individual level.

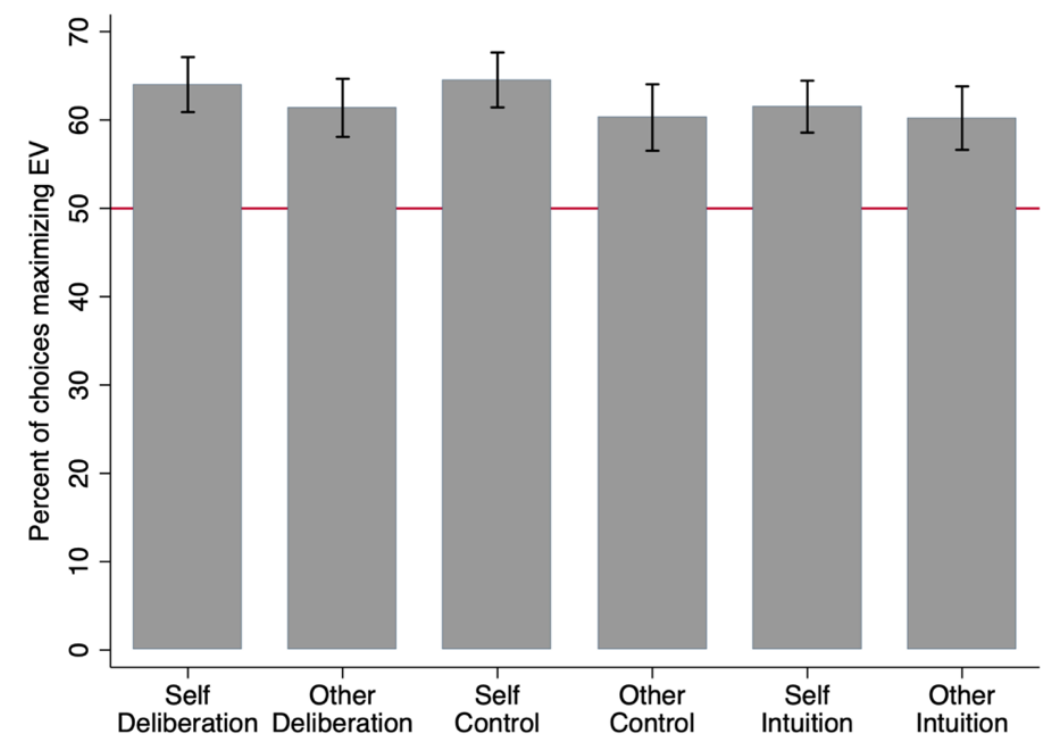

Next, we test the two hypotheses: the dual-process hypothesis that states that decisions for oneself are more intuitive than decisions for others (i.e., greater loss aversion, greater insensitivity to outcomes and probabilities, and greater decision error for Self); alternatively, the utility-maximization hypothesis that states that decisions for oneself involve more cognitive effort than decisions for others (i.e., lower decision error for Self). We estimate CPT parameters using structural estimations and present results in Table $1 .{ }^{14} \mathrm{We}$ find no statistically significant differences between Self and Other in marginal sensitivity to outcomes ( $\mu, p=0.310)$, loss aversion $(\lambda, p=0.158)$, and subjective probability weighting $(\gamma, p=0.151)$. Decision error $(\sigma)$ is significantly greater when deciding on behalf of others than when deciding for oneself $(p=0.004)$.

Comparing risk preferences between treatments, we find no statistically significant differences in marginal sensitivity to outcomes (all $p \geq 0.884$ ). Individuals instructed to deliberate on their choices have a significantly higher loss aversion factor than individuals in control $(p=0.025)$. Individuals in deliberation have significantly lower sensitivity to midrange probabilities than individuals in intuition $(p=0.010)$. Furthermore, individuals deliberating on the decision have lower decision error than individuals making intuitive choices

\footnotetext{
${ }^{14}$ Analysis of risky choices without assumptions about functional form can be found in Appendix B.
} 
$(p=0.016)$. The robustness analysis with respect to beliefs, social value orientation, and empathy can be found in Appendix A.

Table 1: CPT parameter estimates from structural model using maximum likelihood method

Variables:

Other

$\mu$

$(0.086)$

Deliberation

0.017

$(0.117)$

$-0.002$

$(0.125)$

Intuition

$0.885 * * *$

(0.082)

11,498

$\frac{\lambda}{0.827}$

(0.586)

$\gamma$

$(0.081)$

$0.109^{* * *}$

Constant

$1.806 * *$

$-0.330^{*}$

$(0.038)$

(0.806)

(0.183)

$-0.061$

0.314

0.355

$(0.048)$

(0.378)

(0.306)

$0.607 * * *$

$1.026^{* * *}$

0.089

(0.217)

(0.172)

$(0.067)$

$0.320 * * *$

(0.039)

Observations

11,498

11,498

11,498

Note: Constant represents the parameter value for an individual in control treatment making choices for herself.

Standard errors clustered at the subject level in parentheses. ${ }^{* * *} \mathrm{p}<0.01,{ }^{* *} \mathrm{p}<0.05,{ }^{*} \mathrm{p}<0.1$

We summarize the analysis of choice data by relating it to our hypotheses:

Result 1: Our data does not support the hypothesis based on dual-processes. We find no differences in risk preferences when deciding for oneself and on behalf of another person. However, our results are in line with the hypothesis based on utility maximization: we find that decisions for others have greater decision error.

Result 2: In addition, we find that subjects in deliberation display preferences as predicted by prospect theory, i.e., they are more sensitive to losses than subjects in intuition, as well as they are less sensitive to mid-range probabilities (they overweight small probabilities and underweight high probabilities).

Even though we do not find significant differences in risk preferences between Self and Other, we do find a larger decision error when deciding for others. This suggests that individuals make decisions for others roughly according to their own preferences, but these decisions are less consistent. A potential explanation could be that individuals exert less cognitive effort when deciding for others, which should also be reflected in the processing of information. Thus, we turn to information processing analysis to test our hypothesis based on utility maximization whether decisions for oneself involve more cognitive effort than decisions for others (i.e., longer decision time, more fixations, more complete information inspection, longer fixation duration for Self). 


\section{B. Information processing}

We compile the results from information processing analysis in Table 2. Second and third columns of the table present the values of measures for Self and Other respectively (all treatments pooled) and column four lists p-values for Wilcoxon rank sum test between Self and Other. Columns five to seven present the values of measures for each treatment (Self and Other pooled) and the last column lists p-values for Wilcoxon rank sum test between Intuition and Deliberation. As can be seen, decision time, number of fixations, as well as proportion of inspected AOIs differ significantly between Self and Other as well as between Intuition and Deliberation. In the remainder of this section we discuss each of the measures separately in more details. For more detailed illustration of patterns in information processing we refer readers to Figures E2-E6 in Appendix.

Table 2: Summary and comparison of findings from information processing analysis

\begin{tabular}{l|lll|llll} 
Measure & Self & Other & $\mathrm{p}(\mathrm{S}$ vs O) & Deliberation & Control & Intuition & $\mathrm{p}$ (I vs D) \\
\hline \hline $\begin{array}{l}\text { Decision time } \\
(\mathrm{sec})\end{array}$ & 9.69 & 8.36 & $\mathbf{0 . 0 1 5}$ & 10.92 & 9.05 & 7.11 & $<\mathbf{0 . 0 0 1}$ \\
$\mathrm{N}=128$ & & & & & & & \\
\hline $\begin{array}{l}\text { Number of } \\
\text { fixations }\end{array}$ & 30.17 & 24.44 & $\mathbf{0 . 0 1 5}$ & 30.56 & 29.43 & 20.99 & $<\mathbf{0 . 0 0 1}$ \\
$\mathrm{N}=94$ & & & & & & & \\
\hline $\begin{array}{l}\text { Proportion AOI } \\
\mathrm{N}=94\end{array}$ & $86.50 \%$ & $78.84 \%$ & $\mathbf{0 . 0 4 2}$ & $88.07 \%$ & $82.56 \%$ & $76.26 \%$ & $<\mathbf{0 . 0 0 1}$ \\
\hline $\begin{array}{l}\text { Fixation } \\
\text { Duration (msec) } \\
\mathrm{N}=94\end{array}$ & 282.20 & 271.28 & 0.363 & 288.45 & 275.51 & 264.46 & 0.108 \\
& & & & & & & \\
\end{tabular}

Decision time was recorded in z-Tree, and thus we have observations for all 128 subjects and compare Self and Other conditions within subjects. While we did not explicitly ask our subjects to decide fast or slowly, previous research shows that on average intuitive decisions are faster than deliberative decisions. Thus, decision time can serve as an indirect manipulation check. Indeed, individuals instructed to deliberate decided more slowly than individuals instructed to follow their intuition $(p<0.001)$ or individuals in control treatment $(p=0.010)$. Individuals in control treatment also decided more slowly than individuals instructed to follow their intuition $(p=0.006)$. Comparing decisions for Self and Other in all treatments pooled, we find that the decision time for Self is statistically significantly different than the decision time for $\operatorname{Other}(p=0.015)$. This finding holds for individuals in control treatment $(p=0.006)$ but not in deliberation and intuition treatments ( $p=0.192$ and $p=0.772$ respectively). In 
addition, we find that decision time for oneself in control is different than in intuition ( $p=$ 0.002). We do not find evidence that decision time for oneself in control is different than in deliberation $(p=0.102)$. Deciding for other in control treatment was faster than in deliberation ( $p=0.002$ ), but we find no differences when comparing decision time for Other in control and in intuition ( $p=0.455)$.

The remaining information processing measures are based on the gaze data of 94 subjects. We compare Self and Other conditions between subjects. The number of fixations on areas of interest is one of the basic indicators for information integration processes (Horstmann et al. 2009). The number of fixations is greater for Self than for Others in all treatments and this difference is statistically significant in the whole sample $(p=0.015)$ but not within separate treatments. Furthermore, we find that individuals in intuition have less fixations than individuals in deliberation or in control ( $p<0.001$ and $p=0.002$ respectively). There are no differences in the number of fixations between control and deliberation ( $p=0.947)$.

Next, we analyze whether individuals attend to all information available to make a fully informed choice. On average, $82.42 \%$ of all AOIs has been inspected. We find that, on average, individuals attend to more information when deciding for themselves than when deciding for others. This difference is statistically significant in the whole sample $(p=0.042)$ but not within separate treatments. Furthermore, we find a difference in the proportion of inspected AOIs between deliberation and intuition treatments $(p<0.001)$ and between intuition and control treatments $(p=0.009)$.

Lastly, we explore potential self-other differences in the average fixation duration. We do not find differences in fixation duration between Self and Other in any of the treatments or all treatments pooled (all $p>0.210$ ). Furthermore, we fail to reject the hypothesis that the fixation duration is equal across treatments for all pairwise comparisons (all $p>0.108) .{ }^{15}$

As a summary, we highlight our results from the analysis of process data and relate them to our hypotheses:

Result 3: Based on the longer decision time, higher number of fixations, and more complete information inspection, we conclude that individuals use more cognitive processing when making decisions for oneself as compared to making decisions on behalf of the other person.

\footnotetext{
${ }^{15} \mathrm{We}$ inspect the robustness of our results with respect to the definition of a fixation used in the study. We increase the dispersion threshold between any two gaze points from 30 to 40 pixels as well as increase the minimum fixation length from 100 to 117, 133, or 150 milliseconds. The results are presented in table D2 in Appendix. The results concerning the differences between Self and Other are robust to different definitions. Only the differences in the fixation duration between the intuition and deliberation treatments vary when we exclude the shortest fixations.
} 
These findings support the utility maximization hypothesis, which predicts that individuals will spend more cognitive effort on decisions that bring higher potential benefits (here: decisions for oneself).

Result 4: Individuals instructed to deliberate spend more time deciding, have more fixations, and attend to more pieces of information than individuals instructed to use intuition. We find no differences in the average fixation duration between treatments. These results corroborate our dual-processes hypothesis based on (Horstmann et al. 2009), in which deliberative and intuitive decision modes share the same basic processes, supplemented by additional operations in the deliberative processing.

We interpret our results as a support for the utility maximization predictions that decisions for oneself resemble more extensive deliberative processing. Thus, we reject the hypothesis based on dual-processing that decisions for oneself involve more intuitive processing. Our results reveal self-other differences in information processing, while it is still not clear how exactly processing is related to individuals' behavior.

\section{What can information processing tell us about risky choices?}

In this section, we merge the choice data with information processing and investigate whether information processing can explain risky preferences and decision errors. We estimate multiple models in which information processing measures together with a dummy for Other and treatment indicator variables explain each of the risk preference parameters and decision error estimated in section IV.A. Since all information processing measures are significantly correlated with each other and the Pearson's correlation coefficients between these measures are high, we separately estimate one model with each information processing measure (except for fixation duration) as the explanatory variable to avoid multicollinearity problems. The results from structural estimations of CPT parameters using choice and information processing data are listed in Table 3. As can be seen in Model 1, choices for other individuals yield greater decision errors even when controlled for information processing. The decision error, however, is reduced by more extensive processing, i.e., when individuals have longer decision time (Model 1) or conduct more complete information inspection (Model 3). Further, the number of fixations does not have a significant impact on decision error. This leads us to final result, which is explorative in nature: 
Result 5: Information processing is not related to risk preferences, but is negatively related to decision error. The decision error is lower when individuals spend more time making decisions or inspect more information.

Table 3: CPT parameter estimates explained with experimental indicators and information processing data

\begin{tabular}{|c|c|c|c|c|}
\hline Variables: & $\mu$ & $\lambda$ & $\gamma$ & $\sigma$ \\
\hline \multicolumn{5}{|l|}{ Model 1} \\
\hline \multirow[t]{2}{*}{ Other } & 0.061 & 0.843 & 0.103 & $0.087^{* *}$ \\
\hline & $(0.088)$ & $(0.575)$ & $(0.076)$ & $(0.039)$ \\
\hline \multirow[t]{2}{*}{ Deliberation } & 0.024 & $1.826 * *$ & $-0.313^{*}$ & -0.056 \\
\hline & $(0.113)$ & $(0.770)$ & $(0.175)$ & $(0.042)$ \\
\hline \multirow[t]{2}{*}{ Intuition } & -0.002 & 0.362 & 0.354 & 0.073 \\
\hline & $(0.124)$ & $(0.385)$ & $(0.293)$ & $(0.066)$ \\
\hline \multirow[t]{2}{*}{ Decision Time } & 0.000 & 0.010 & 0.002 & $-0.004 * * *$ \\
\hline & $(0.004)$ & $(0.036)$ & $(0.004)$ & $(0.001)$ \\
\hline \multirow[t]{2}{*}{ Constant } & $0.891 * * *$ & 0.479 & $1.005 * * *$ & $0.364 * * *$ \\
\hline & $(0.101)$ & $(0.451)$ & $(0.174)$ & $(0.046)$ \\
\hline Observations & 11,498 & 11,498 & 11,498 & 11,498 \\
\hline \multicolumn{5}{|l|}{ Model 2} \\
\hline \multirow[t]{2}{*}{ Other } & -0.055 & 0.443 & -0.253 & 0.074 \\
\hline & $(0.130)$ & $(0.950)$ & $(0.218)$ & $(0.070)$ \\
\hline \multirow[t]{2}{*}{ Deliberation } & 0.119 & 1.382 & -0.194 & -0.020 \\
\hline & $(0.125)$ & $(0.855)$ & $(0.241)$ & $(0.058)$ \\
\hline \multirow[t]{2}{*}{ Intuition } & -0.072 & 0.018 & 0.105 & 0.223 \\
\hline & $(0.148)$ & $(0.852)$ & $(0.393)$ & $(0.148)$ \\
\hline \multirow[t]{2}{*}{ Number of Fixations } & 0.001 & 0.000 & -0.006 & -0.000 \\
\hline & $(0.004)$ & $(0.012)$ & $(0.005)$ & $(0.001)$ \\
\hline \multirow[t]{2}{*}{ Constant } & $0.878 * * *$ & 0.712 & $1.479 * * *$ & $0.280 * * *$ \\
\hline & $(0.145)$ & $(0.479)$ & $(0.273)$ & $(0.056)$ \\
\hline Observations & 4,190 & 4,190 & 4,190 & 4,190 \\
\hline \multicolumn{5}{|l|}{ Model 3} \\
\hline \multirow[t]{2}{*}{ Other } & -0.093 & 0.456 & -0.151 & 0.071 \\
\hline & $(0.107)$ & $(0.884)$ & $(0.205)$ & $(0.060)$ \\
\hline \multirow[t]{2}{*}{ Deliberation } & 0.145 & $1.407^{*}$ & -0.089 & 0.002 \\
\hline & $(0.117)$ & $(0.778)$ & $(0.204)$ & $(0.046)$ \\
\hline \multirow[t]{2}{*}{ Intuition } & -0.065 & 0.033 & 0.200 & 0.244 \\
\hline & $(0.143)$ & $(0.884)$ & $(0.368)$ & $(0.151)$ \\
\hline \multirow[t]{2}{*}{ Proportion AOI } & $-0.583 * *$ & 0.229 & -1.107 & $-0.350 * *$ \\
\hline & $(0.294)$ & $(0.670)$ & $(0.751)$ & $(0.177)$ \\
\hline \multirow[t]{2}{*}{ Constant } & $1.417 * * *$ & 0.502 & $2.188 * * *$ & $0.564 * * *$ \\
\hline & $(0.268)$ & $(0.639)$ & $(0.688)$ & $(0.170)$ \\
\hline Observations & 4,190 & 4,190 & 4,190 & 4,190 \\
\hline
\end{tabular}

Note: Constant represents the parameter value for an individual in control treatment making choices for herself. Standard errors clustered at the subject level in parentheses. ${ }^{* * *} \mathrm{p}<0.01,{ }^{* *} \mathrm{p}<0.05,{ }^{*} \mathrm{p}<0.1$

\section{Conclusion and Discussion}

As deciding on behalf of others is prevalent in modern society, it is important to explore whether decisions made for others differ in a systematic way from decisions made for oneself. Both risk preferences and decision error can have important implications for the welfare of 
others. The literature on this topic yields contradicting results but also suggests many possible channels for these discrepancies. This study investigates not only which, but also how the decisions for oneself and for others are made.

We find no differences in risk preferences between choices made for oneself and someone else. However, we find that choices made for others are less consistent, i.e., have higher decision errors. Decision errors are particularly relevant in the delegated decisionmaking. Many environments in which individuals make decisions for others (e.g., medicine, finance, project management) involve elements of uncertainty and unpredictability and require decision makers to rely on judgement calls. Judgement calls, as opposed to hard facts, give a lot of opportunities for decision noise. The idea that noise cancels out because its mean tends toward zero is misleading - noise, similarly to other types of errors is additive. Greater noise implies more mistakes. In their article discussing the implications of noisy decisions, Kahneman et al. (2016) call noise a hidden cost of inconsistent decision making. The noise of the decisions can take a serious toll in terms of money (e.g., in financial decision making) or even lives (e.g., in clinical decision making). It can lead to unfairness in the society (e.g., when two patients with the same medical problem are assigned different treatments) and in general reduces the quality of decisions for others. The alarming consequences of low decision consistency have been exemplified in a study on clinical decision making, in which doctors gave different cancer diagnosis after seeing the same X-ray two times (Goldberg 1968).

In addition, our analysis of processing data reveals that when deciding for oneself individuals spend more time on deciding, have more fixations, and inspect more information pieces (i.e., conduct a more complete information search). Further, we find no differences in the average fixation duration between decisions for oneself and others. We conclude that individuals process less information when deciding for others, while basic processes do not differ between decisions for self and other. Similar processing patterns are found when comparing information processing in deliberation treatment with intuition treatment (in line with Horstmann et al. 2009). This implies that the processing of decisions for oneself resembles more extensive deliberation. Lastly, we find that conducting more effortful processing is related to lower decision errors. When controlling for decision time, we still find a difference in decision error for self-other choices.

Our results are in line with predictions based on the utility maximization approach when cognitive effort is costly, i.e., individuals spend less cognitive resources when deciding for others. However, we do not claim that decisions for others are made using mainly intuitive processing. The average decision time when deciding for others in control treatment was above 
$7 \mathrm{~s}$, which in comparison with previous studies is relatively long and can be sufficient to deliberate on the decision (Myrseth and Wollbrant 2016; Krajbich et al. 2015).

We find that being personally involved did not result in more intuitive responses, but rather the opposite. Our results do not exclude the possibility that individuals were more emotionally affected when deciding for themselves than for other individuals. It is possible that more affect does not necessarily imply intuitive decision making and that emotions and deliberative processing are not mutually exclusive. For example, attaching more feelings to own outcomes rather than the outcomes of strangers can motivate individuals to put more deliberative effort to make decisions for themselves (Peters 2006).

Our finding about greater decision error when deciding for others is in line with a recent work by Eriksen et al. (2017) who find that risky decisions made on behalf of others in three different tasks are highly inconsistent, i.e. the same individuals take sometimes more and sometimes less risks on behalf of another person than for themselves. These results point that the design of the risk elicitation task might contribute to the differences in previous findings about decision making for oneself and on behalf of others. Andersson et al. (2016b) show that estimating risk preferences without accounting for decision error can yield the risk of wrongly inferring the risk aversion level. Depending on the calibration of lotteries in the experimental task, subjects who make less consistent choices can be either classified as more risk averse or risk seeking if, by design, erroneous choices are more likely in the respective direction. In their study, Andersson et al. (2016b) demonstrate that the choice of a risk task and its calibration might create spurious correlations between risk preferences and cognitive ability, while in fact cognitive ability relates to the decision error. We find that deciding on behalf of others and conducting less information processing also relate to a greater decision error. Given that individuals make more random choices for others, they will seem to be more risk averse with other people's money than with their own money if the available choice alternatives are biased towards risk aversion. Similarly, they will seem to be more risk seeking if there are more chances to err towards the risky option than a safe one.

The findings of our study contribute to the debate on self-other differences in risky decisions. Previously, Vieider et al. (2016) and Andersson et al. (2016a) used structural model approach to analyze self-other differences. Vieider et al. (2016) elicit certainty equivalents (CE) and divide subjects into two treatments where people make decisions either for themselves or for themselves and another person. In general, Vieider et al. (2016) find that the outcome sensitivity parameter is close to unity and does not differ between treatments. Loss aversion parameter is low ( $\lambda$ around 0.7 ) and also does not differ significantly between treatments. In 
addition, they find lower sensitivity to midrange probabilities when deciding for other and oneself (with $\gamma$ values ranging between 0.53 and 0.84 ) and no differences in decision error between treatments $(\sigma \approx 0.2)$. These parameter values are similar to values found in our study. In turn, Andersson et al. (2016a) use a multiple-price-list (MPL) task and estimate constant relative risk-aversion model (CRRA) with loss aversion. They find no self-other differences in sensitivity to outcomes and decision error, but greater sensitivity to losses in decisions made for oneself. Similar to these studies, we do not find any differences in sensitivity to outcomes. However, this is where the similarities end. We do not find any self-other differences in loss aversion as in Andersson et al. (2016a). This might stem from the fact that their model does not account for probability weighting as argued by Vieider et al. (2016). Further, our results do not point to differences in probabilistic sensitivity, but in turn point to differences in decision error, in contrast with Vieider et al. (2016). The differences between our studies could result from the choice of the task used to elicit risk preferences. Both of the mentioned studies use simple tasks with maximally two outcomes for each lottery and simple probability calculations, e.g. in CE elicitation one of the outcomes is always safe and in MPL each outcome can happen with 50\% probability. In turn, our lotteries involve three possible outcomes and vary in probabilities. Thus, the self-other difference in decision error might be caused by the fact that our task is more complex and thus requires more cognitive resources to process. In addition, Pedroni et al. (2017) show that risk preferences are not consistent across different elicitation methods, thus making the comparison between studies more difficult.

We only explore how cognitive processing can contribute to self-other differences when the "other" is a random stranger who remains unknown. The results can differ if the other person is known to the decision maker, for instance, a friend or a relative. For example, Montinari and Rancan (2013) show that social distance is a relevant factor in deciding for others. Liu et al. (2018) find that subjects search for more information when deciding for a close friend which is in contrast to our results. However, they discuss the possibility that social distance might influence their results and information search patterns can change as the social distance increases. These results can be reconciled with our hypothesis based on utility maximization, whereby individuals derive greater utility when making their friends satisfied and happy. More extensive research is needed to establish how varying the degree of social distance affects information processing and behavior when deciding for others.

The results from our study can help improve the quality of delegated risky decision making. While we find that individuals are not very good at integrating information in a robust way, more extensive deliberation can reduce decision errors. Noise (decision error) is always 
undesirable and sometimes might be even disastrous. This is especially important in professional settings that require individual's judgement and entail a significant degree of uncertainty and unpredictability, such as medicine, finance, or project management. For example, due to decision error, two customers with similar characteristics and preferences might be offered stock portfolios with completely different levels of risk. Hence, it is important to encourage individuals who decide for others to conduct a more complete, reflective processing.

\section{Acknowledgements}

The authors gratefully acknowledge financial support from Graduate School of Decision Science (GSDS) at the University of Konstanz. This study was presented at the First BEGG Workshop on Behavioural and Experimental Economics 2016, the Arne Ryde Workshop 2016, Egproc 2016, the Society for Neuroeconomics Meeting 2016, the ESA European Meeting 2016, the TWI Kreuzlingen, and Decision Making for Others (Nijmegen 2018). We thank the participants for their input. We also thank Pablo Brañas-Garza, Ola Andersson, Susann Fiedler, Urs Fischbacher, Manja Gärtner, Peter Martinsson, Gustav Tinghög, Conny Wollbrant, two anonymous reviewers, and the editors of this special issue for their valuable comments. 


\section{References}

Alós-Ferrer, Carlos. 2018. 'A Dual-Process Diffusion Model', Journal of Behavioral Decision Making, 31: 203-18.

Alós-Ferrer, Carlos, and Sabine Hügelschäfer. 2012. 'Faith in intuition and behavioral biases', Journal of Economic Behavior \& Organization, 84: 182-92.

. 2016. 'Faith in intuition and cognitive reflection', Journal of Behavioral and Experimental Economics, 64: 61-70.

Alós-Ferrer, Carlos, and Fritz Strack. 2014. 'From dual processes to multiple selves: Implications for economic behavior', Journal of Economic Psychology, 41: 1-11.

Andersson, Ola, Håkan J. Holm, Jean-Robert Tyran, and Erik Wengström. 2016a. 'Deciding for Others Reduces Loss Aversion', Management Science, 62: 29-36.

- 2016b. 'Risk Aversion Relates to Cognitive Ability: Preferences or Noise?', Journal of the European Economic Association, 14: 1129-54.

Apesteguia, Jose, and Miguel A. Ballester. 2018. 'Monotone Stochastic Choice Models: The Case of Risk and Time Preferences', Journal of Political Economy, 126: 74-106.

Azrieli, Yaron, Christopher P. Chambers, and Paul J. Healy. 2018. 'Incentives in Experiments: A Theoretical Analysis', Journal of Political Economy, 126: 1472-503.

Becker, Gary S. 1962. 'Irrational Behavior and Economic Theory', Journal of Political Economy, 70: 1-13.

Betsch, Cornelia. 2004. 'Präferenz für Intuition und Deliberation (PID): Inventar zur Erfassung von affekt- und kognitionsbasiertem Entscheiden. [Preference for Intuition and Deliberation (PID): An Inventory for Assessing Affect- and Cognition-Based Decision-Making.]', Zeitschrift für Differentielle und Diagnostische Psychologie, 25: 179-97.

Bieleke, Maik, Peter M. Gollwitzer, Gabriele Oettingen, and Urs Fischbacher. 2017. 'Social Value Orientation Moderates the Effects of Intuition versus Reflection on Responses to Unfair Ultimatum Offers', Journal of Behavioral Decision Making, 30: 569-81.

Blignaut, Pieter. 2009. 'Fixation identification: The optimum threshold for a dispersion algorithm', Attention, Perception, \& Psychophysics, 71: 881-95.

Bolton, Gary E., Axel Ockenfels, and Julia Stauf. 2015. 'Social responsibility promotes conservative risk behavior', European Economic Review, 74: 109-27.

Bruhin, Adrian, Helga Fehr-Duda, and Thomas Epper. 2010. 'Risk and Rationality: Uncovering Heterogeneity in Probability Distortion', Econometrica, 78: 1375-412.

Camerer, Colin F., and Robin M. Hogarth. 1999. 'The Effects of Financial Incentives in Experiments: A Review and Capital-Labor-Production Framework', Journal of Risk and Uncertainty, 19: 7-42. 
Caplin, Andrew, Mark Dean, and Daniel Martin. 2011. 'Search and Satisficing', American Economic Review, 101: 2899-922.

Caplin, Andrew, and Daniel Martin. 2016. 'The Dual-process Drift Diffusion Model: Evidence from Response Times', Economic Inquiry, 54: 1274-82.

Chakravarty, Sujoy, Glenn W. Harrison, Ernan E. Haruvy, Rutstr, xf, and E. Elisabet m. 2011. 'Are You Risk Averse over Other People's Money?', Southern Economic Journal, 77: 901-13.

Charness, Gary, Uri Gneezy, and Brianna Halladay. 2016. 'Experimental methods: Pay one or pay all', Journal of Economic Behavior \& Organization, 131: 141-50.

Conlisk, John. 1996. 'Why Bounded Rationality?', Journal of Economic Literature, 34: 669700.

Cooper, David, and John H Kagel. 2012. 'Other regarding preferences: a selective survey of experimental results.' in John H Kagel and Alvin Roth (eds.), Handbook of Experimental Economics, vol. 2 (Princeton University Press: Princeton).

Dalmaijer, Edwin S., Sebastiaan Mathôt, and Stefan Van der Stigchel. 2014. 'PyGaze: An opensource, cross-platform toolbox for minimal-effort programming of eyetracking experiments', Behavior Research Methods, 46: 913-21.

Davis, M. 1980. 'A multidimensional approach to individual differences in empathy', JSAS Catalog of Selected Documents in Psychology, 10: 85-103.

Devetag, Giovanna, Sibilla Di Guida, and Luca Polonio. 2016. 'An eye-tracking study of feature-based choice in one-shot games', Experimental Economics, 19: 177-201.

Epstein, Seymour. 1994. 'Integration of the cognitive and the psychodynamic unconscious', American Psychologist, 49: 709-24.

Eriksen, Kristoffer W., and Ola Kvaløy. 2010. 'Myopic Investment Management', Review of Finance, 14: 521-42.

Eriksen, Kristoffer W., Ola Kvaløy, and Miguel Luzuriaga. 2017. "Risk-Taking on Behalf of Others " In CESifo Working Paper Series No. 6378.

Etchart-Vincent, Nathalie, and Olivier l'Haridon. 2011. 'Monetary incentives in the loss domain and behavior toward risk: An experimental comparison of three reward schemes including real losses', Journal of Risk and Uncertainty, 42: 61-83.

Faro, David, and Yuval Rottenstreich. 2006. 'Affect, Empathy, and Regressive Mispredictions of Others' Preferences Under Risk', Management Science, 52: 529-41.

Fiedler, Susann, and Andreas Glöckner. 2012. 'The Dynamics of Decision Making in Risky Choice: An Eye-Tracking Analysis', Frontiers in Psychology, 3: 335.

2015. 'Attention and moral behavior', Current Opinion in Psychology, 6: 139-44. 
Fiedler, Susann, Andreas Glöckner, Andreas Nicklisch, and Stephan Dickert. 2013. 'Social Value Orientation and information search in social dilemmas: An eye-tracking analysis', Organizational Behavior and Human Decision Processes, 120: 272-84.

Fischbacher, Urs. 2007. 'z-Tree: Zurich toolbox for ready-made economic experiments', Experimental Economics, 10: 171-78.

Füllbrunn, Sascha C., and Wolfgang J. Luhan. 2017. 'Decision making for others: The case of loss aversion', Economics Letters, 161: 154-56.

Ghaffari, Minou, and Susann Fiedler. 2018. 'The Power of Attention: Using Eye Gaze to Predict Other-Regarding and Moral Choices', Psychological Science, 29: 1878-89.

Gneezy, Uri, and Jan Potters. 1997. 'An Experiment on Risk Taking and Evaluation Periods', The Quarterly Journal of Economics, 112: 631-45.

Goldberg, Lewis R. 1968. 'Simple models or simple processes? Some research on clinical judgments', American Psychologist, 23: 483-96.

Gollwitzer, Peter M. 1999. 'Implementation intentions: Strong effects of simple plans', American Psychologist, 54: 493-503.

Gollwitzer, Peter M., and Paschal Sheeran. 2006. 'Implementation Intentions and Goal Achievement: A Meta-analysis of Effects and Processes.' in, Advances in Experimental Social Psychology (Academic Press).

Greiner, Ben. 2015. 'Subject pool recruitment procedures: organizing experiments with ORSEE', Journal of the Economic Science Association, 1: 114-25.

Halberstadt, Jamin Brett, and Gary M. Levine. 1999. 'Effects of Reasons Analysis on the Accuracy of Predicting Basketball Games', Journal of Applied Social Psychology, 29: 517-30.

Harrison, Glenn W., John A. List, and Charles Towe. 2007. 'Naturally Occurring Preferences and Exogenous Laboratory Experiments: A Case Study of Risk Aversion', Econometrica, 75: 433-58.

Harrison, Glenn W., and E. Elisabet Rutström. 2008. 'Expected utility theory and prospect theory: one wedding and a decent funeral', Experimental Economics, 12: 133.

Hausfeld, Jan, and Sven Resnjanskij. 2017. "Risky Decisions and the Opportunity Costs of Time." In TWI Research Paper Series. Thurgauer Wirtschaftsinstitut, Universität Konstanz.

Hertwig, Ralph, and Andreas Ortmann. 2001. 'Experimental practices in economics: A methodological challenge for psychologists?', Behavioral and Brain Sciences, 24: 383-451.

Hey, John D., and Chris Orme. 1994. 'Investigating Generalizations of Expected Utility Theory Using Experimental Data', Econometrica, 62: 1291-326.

Hochman, Guy, Andreas Glöckner, Susann Fiedler, and Shahar Ayal. 2016. '"I can see it in your eyes": Biased Processing and Increased Arousal in Dishonest Responses', Journal of Behavioral Decision Making, 29: 322-35. 
Holmqvist, Kenneth, Marcus Nyström, Richard Andersson, Richard Dewhurst, Halszka Jarodzka, and Joost Van de Weijer. 2011. Eye tracking: A comprehensive guide to methods and measures (OUP Oxford).

Holmqvist, Kenneth, Marcus Nyström, and Fiona Mulvey. 2012. "Eye tracker data quality: What it is and how to measure it." In Proceedings of the Symposium on Eye Tracking Research and Applications, 45-52. Santa Barbara, California: ACM.

Horstmann, Nina, Andrea Ahlgrimm, and Andreas Glöckner. 2009. 'How distinct are intuition and deliberation? An eye-tracking analysis of instruction-induced decision modes', Judgment and Decision Making, 4: 335-54.

Hsee, Christopher K., and Yuval Rottenstreich. 2004. 'Music, Pandas, and Muggers: On the Affective Psychology of Value', Journal of Experimental Psychology: General, 133: 23-30.

Jiang, Ting, Jan Potters, and Yukihiko Funaki. 2016. 'Eye-tracking Social Preferences', Journal of Behavioral Decision Making, 29: 157-68.

Jung, Daehyun, Sunhae Sul, and Hackjin Kim. 2013. 'Dissociable Neural Processes Underlying Risky Decisions for Self Versus Other', Frontiers in Neuroscience, 7: 15.

Kahneman, Daniel. 2003. 'A perspective on judgment and choice: Mapping bounded rationality', American Psychologist, 58: 697-720.

Kahneman, Daniel, Andrew M Rosenfield, Linnea Gandhi, and Tom Blaser. 2016. 'NOISE: How to overcome the high, hidden cost of inconsistent decision making', Harvard business review, 94: 38-46.

Kirchler, Michael, David Andersson, Caroline Bonn, Magnus Johannesson, Erik Ø Sørensen, Matthias Stefan, Gustav Tinghög, and Daniel Västfjäll. 2017. 'The effect of fast and slow decisions on risk taking', Journal of Risk and Uncertainty, 54: 37-59.

Klein, Howard J., Michael J. Wesson, John R. Hollenbeck, Patrick M. Wright, and Richard P. DeShon. 2001. 'The Assessment of Goal Commitment: A Measurement Model Meta-Analysis', Organizational Behavior and Human Decision Processes, 85: 32-55.

Kool, Wouter, Joseph T. McGuire, Zev B. Rosen, and Matthew M. Botvinick. 2010. 'Decision making and the avoidance of cognitive demand', Journal of Experimental Psychology: General, 139: $665-82$.

Krajbich, Ian, Carrie Armel, and Antonio Rangel. 2010. 'Visual fixations and the computation and comparison of value in simple choice', Nature Neuroscience, 13: 1292.

Krajbich, Ian, Björn Bartling, Todd Hare, and Ernst Fehr. 2015. 'Rethinking fast and slow based on a critique of reaction-time reverse inference', 6: 7455.

Laury, Susan. 2006. "Pay One or Pay All: Random Selection of One Choice for Payment." In.: Experimental Economics Center, Andrew Young School of Policy Studies ....

Leder, Johannes, and Tilmann Betsch. 2016. 'Risky choice in interpersonal context: Do people dare because they care?', Journal of Economic Psychology, 52: 1-23. 
Liu, Yi, Evan Polman, Yongfang Liu, and Jiangli Jiao. 2018. 'Choosing for others and its relation to information search', Organizational Behavior and Human Decision Processes, 147: $65-75$.

Loewenstein, George. 2000. 'Emotions in Economic Theory and Economic Behavior', The American Economic Review, 90: 426-32.

Loewenstein, George F., Elke U. Weber, Christopher K. Hsee, and Ned Welch. 2001. 'Risk as feelings', Psychological Bulletin, 127: 267-86.

Lu, Jingyi, Huiyuan Jia, Xiaofei Xie, and Qiuhong Wang. 2016. 'Missing the best opportunity; who can seize the next one? Agents show less inaction inertia than personal decision makers', Journal of Economic Psychology, 54: 100-12.

Mengarelli, Flavia, Laura Moretti, Valeria Faralla, Philippe Vindras, and Angela Sirigu. 2014. 'Economic Decisions for Others: An Exception to Loss Aversion Law', PLOS ONE, 9: e85042.

Montinari, Natalia, and Michaela Rancan. 2013. "Social preferences under risk: the role of social distance." In.: Jena Economic Research Papers.

Murphy, Ryan O, Kurt A Ackermann, and Michel Handgraaf. 2011. 'Measuring social value orientation', Judgement and Decision Making, 6: 771-81.

Myrseth, Kristian O. R., and Conny E. Wollbrant. 2016. 'Commentary: Fairness is intuitive', Frontiers in Psychology, 7.

Orquin, Jacob L., Nathaniel J. S. Ashby, and Alasdair D. F. Clarke. 2016. 'Areas of Interest as a Signal Detection Problem in Behavioral Eye-Tracking Research', Journal of Behavioral Decision Making, 29: 103-15.

Orquin, Jacob L., and Simone Mueller Loose. 2013. 'Attention and choice: A review on eye movements in decision making', Acta Psychologica, 144: 190-206.

Pacini, Rosemary, and Seymour Epstein. 1999. 'The relation of rational and experiential information processing styles to personality, basic beliefs, and the ratio-bias phenomenon', Journal of Personality and Social Psychology, 76: 972-87.

Pahlke, Julius, Sebastian Strasser, and Ferdinand M. Vieider. 2012. 'Risk-taking for others under accountability', Economics Letters, 114: 102-05.

- 2015. 'Responsibility effects in decision making under risk', Journal of Risk and Uncertainty, 51: 125-46.

Pedroni, Andreas, Renato Frey, Adrian Bruhin, Gilles Dutilh, Ralph Hertwig, and Jörg Rieskamp. 2017. 'The risk elicitation puzzle', Nature Human Behaviour, 1: 803-09.

Peters, Ellen. 2006. 'The functions of affect in the construction of preferences.' in Sara Lichtenstein and Paul Slovic (eds.), The construction of preference (Cambridge University Press: New York).

Pollmann, Monique M. H., Jan Potters, and Stefan T. Trautmann. 2014. 'Risk taking by agents: The role of ex-ante and ex-post accountability', Economics Letters, 123: 387-90. 
Polman, Evan. 2012. 'Self-other decision making and loss aversion', Organizational Behavior and Human Decision Processes, 119: 141-50.

Polonio, Luca, Sibilla Di Guida, and Giorgio Coricelli. 2015. 'Strategic sophistication and attention in games: An eye-tracking study', Games and Economic Behavior, 94: 80-96.

Prelec, Drazen. 1998. 'The Probability Weighting Function', Econometrica, 66: 497-527.

Reutskaja, Elena, Rosemarie Nagel, Colin F. Camerer, and Antonio Rangel. 2011. 'Search Dynamics in Consumer Choice under Time Pressure: An Eye-Tracking Study', American Economic Review, 101: 900-26.

Reynolds, Douglas B., Jacob Joseph, and Reuben Sherwood. 2011. 'Risky Shift Versus Cautious Shift: Determining Differences In Risk Taking Between Private And Public Management Decision-Making', Journal of Business \& Economics Research (JBER), 7.

Rick, Scott, and George Loewenstein. 2008. 'The Role of Emotion in Economic Behavior.' in Michael Lewis, Jeanette M. Haviland-Jones and Lisa Feldman Barett (eds.), Handbook of Emotions (The Guilford Press: New York).

Rottenstreich, Yuval, and Christopher K. Hsee. 2001. 'Money, Kisses, and Electric Shocks: On the Affective Psychology of Risk', Psychological Science, 12: 185-90.

Salvucci, Dario D, and Joseph H Goldberg. 2000. "Identifying fixations and saccades in eyetracking protocols." In Proceedings of the 2000 symposium on Eye tracking research \& applications, 71-78. ACM.

Shimojo, Shinsuke, Claudiu Simion, Eiko Shimojo, and Christian Scheier. 2003. 'Gaze bias both reflects and influences preference', Nature Neuroscience, 6: 1317.

Sickmann, Jörn, and Huynh Bich Ngan Le. 2016. 'Eye-Tracking in Behavioural Economics and finance - A literature review', Discussion Papers in Behavioural Sciences and Economics, 2016.

Simon, Herbert A. 1955. 'A Behavioral Model of Rational Choice', The Quarterly Journal of Economics, 69: 99-118.

American Economic Review, 49: 253-83.

Sloman, Steven A. 1996. 'The empirical case for two systems of reasoning', Psychological Bulletin, 119: 3-22.

Slovic, Paul, Melissa Finucane, Ellen Peters, and Donald G. MacGregor. 2002. 'The Affect Heuristic.' in Dale Griffin, Daniel Kahneman and Thomas Gilovich (eds.), Heuristics and Biases: The Psychology of Intuitive Judgment (Cambridge University Press: Cambridge).

Smith, Vernon, and James Walker. 1993. 'Monetary Rewards and Decision Cost in Experimental Economics', Economic Inquiry, 31: 245-61.

Starmer, Chris. 2000. 'Developments in Non-Expected Utility Theory: The Hunt for a Descriptive Theory of Choice under Risk', Journal of Economic Literature, 38: 332-82. 
Starmer, Chris, and Robert Sugden. 1991. 'Does the Random-Lottery Incentive System Elicit True Preferences? An Experimental Investigation', The American Economic Review, 81: 97178.

Stewart, Neil, Frouke Hermens, and William J. Matthews. 2016. 'Eye Movements in Risky Choice', Journal of Behavioral Decision Making, 29: 116-36.

Stott, Henry P. 2006. 'Cumulative prospect theory's functional menagerie', Journal of Risk and Uncertainty, 32: 101-30.

Thaler, Richard. 1980. 'Toward a positive theory of consumer choice', Journal of Economic Behavior \& Organization, 1: 39-60.

Thaler, Richard H., and Eric J. Johnson. 1990. 'Gambling with the House Money and Trying to Break Even: The Effects of Prior Outcomes on Risky Choice', Management Science, 36: 64360 .

Tversky, Amos, and Daniel Kahneman. 1986. 'Rational Choice and the Framing of Decisions', The Journal of Business, 59: S251-S78.

1992. 'Advances in Prospect Theory: Cumulative Representation of Uncertainty', Journal of Risk and Uncertainty, 5: 297-323.

Vieider, Ferdinand M., Clara Villegas-Palacio, Peter Martinsson, and Milagros Mejía. 2016. 'Risk Taking for Oneself and Others: A Structural Model Approach', Economic Inquiry, 54: 879-94.

Wakker, Peter P. 2008. 'Explaining the characteristics of the power (CRRA) utility family', Health Economics, 17: 1329-44.

Wang, Joseph Tao-yi, Michael Spezio, and Colin F. Camerer. 2010. 'Pinocchio's Pupil: Using Eyetracking and Pupil Dilation to Understand Truth Telling and Deception in Sender-Receiver Games', The American Economic Review, 100: 984-1007.

Wilcox, Nathaniel T. 2011. 'Stochastically more risk averse:' A contextual theory of stochastic discrete choice under risk', Journal of Econometrics, 162: 89-104.

Witteman, Cilia, John van den Bercken, Laurence Claes, and Antonio Godoy. 2009. 'Assessing Rational and Intuitive Thinking Styles', European Journal of Psychological Assessment, 25: $39-47$. 


\section{Appendix}

\section{A. Eye Tracking Specifics}

We decided to use a maximum calibration error of $0.9^{\circ}$ as this fits well with our screen size and results in non-overlapping areas of interest (AOIs). Holmqvist et al. (2011) report that usually the measured accuracy values range between $0.3^{\circ}$ and $2^{\circ}$. As explained in the Method section, we used a minimum time of $101 \mathrm{~ms}$ and a 30-pixel dispersion threshold. Given our choice of maximum calibrated accuracy to a visual angle of $0.9^{\circ}, 30$-pixel dispersion threshold is in line with the suggestion of Salvucci and Goldberg (2000) of a threshold between $0.5^{\circ}$ and $1^{\circ}$. Higher minimum fixation lengths (e.g., 117 or $133 \mathrm{~ms}$ ) yield less fixations (roughly $7.5 \%$ of fixations have length around $101 \mathrm{~ms}$, while roughly $4.4 \%$ are each of 116 or $132 \mathrm{~ms}$ length). In each fixation, we calculate the median coordinate for both the width and height. In the analysis, we only used fixations that were within areas of interest (AOI) based on the boxes containing the probabilities and outcomes.

We used circular AOIs of 90-pixel radius from the center of the text. The inspection of the first three trials of each subject revealed that subjects looked at the lottery labels (Option 1 and Option 2). As these boxes were close to the bottom boxes with outcomes and probabilities, the 90-pixel radius yielded AOIs that did not overlap with lottery labels (see Orquin et al. 2016 for a discussion on AOI sizes).

Several subjects failed calibration after multiple attempts. Data loss due to calibration problems is typical for eye-tracking studies and the proportion of subjects dropped from eyetracking analysis in our study is within the values found in previous studies (Holmqvist et al. 2012). The individuals who had problems with calibrations were randomly distributed over sessions and treatments. The problems with calibration could be caused, for example, by droopy eyelids, downward eyelashes etc. These are believed to not be correlated with risk taking. In addition, we have missing eye-tracking data for the total of 40 decisions spread across 94 subjects which could be due to subjects squinting their eyes or moving their head too much.

\section{B. Risk preferences without parametrical restrictions}

In this section we test whether there are differences in risk taking between Self and Other without assuming the functional form of individual's risk preferences. We analyze how frequently individuals choose the safer option as defined by Wilcox (2011). Let $x=\left(x_{1}, x_{2}, x_{3}\right)$ be a vector of three monetary outcomes where $x_{1}<x_{2}<x_{3} ; P_{A}=\left(A_{1}, A_{2}, A_{3}\right)$ the probability distribution over the vector of outcomes $x$ in lottery A; and $P_{B}=\left(B_{1}, B_{2}, B_{3}\right)$ the probability 
distribution over the vector of outcomes $x$ in lottery B. Lottery A is said to be safer than lottery B if $A_{2}+A_{3}>B_{2}+B_{3}$ and $A_{3}<B_{3}$ in a sense that lottery $\mathrm{A}$ has more chance of the center outcome and less chance of the extreme outcomes. Figure B1 illustrates proportion of safer choices in each of the treatments and conditions. There are no statistical differences between Self and Other in each of the treatments or all treatments pooled (all $p>0.165$ ). As can be seen in the figure, the proportion of safer choices in control and intuition treatments in both Self and Other conditions are not statistically different from 50\% (i.e., they are as good as random). However, the proportion of safer choices in deliberation treatment is close to $60 \%$ and is significantly different from 50\%. In fact, when we pool Self and Other choices, the proportion of safer choices is statistically significantly different in deliberation than in intuition $(p<$ $0.001)$ and in control $(p=0.004)$.

Figure B1: Proportion of safer choices by treatment for Self and Other $(n=128)$. Error bars indicate the $95 \%$ confidence interval of the means accounting for the clustering at the individual level.

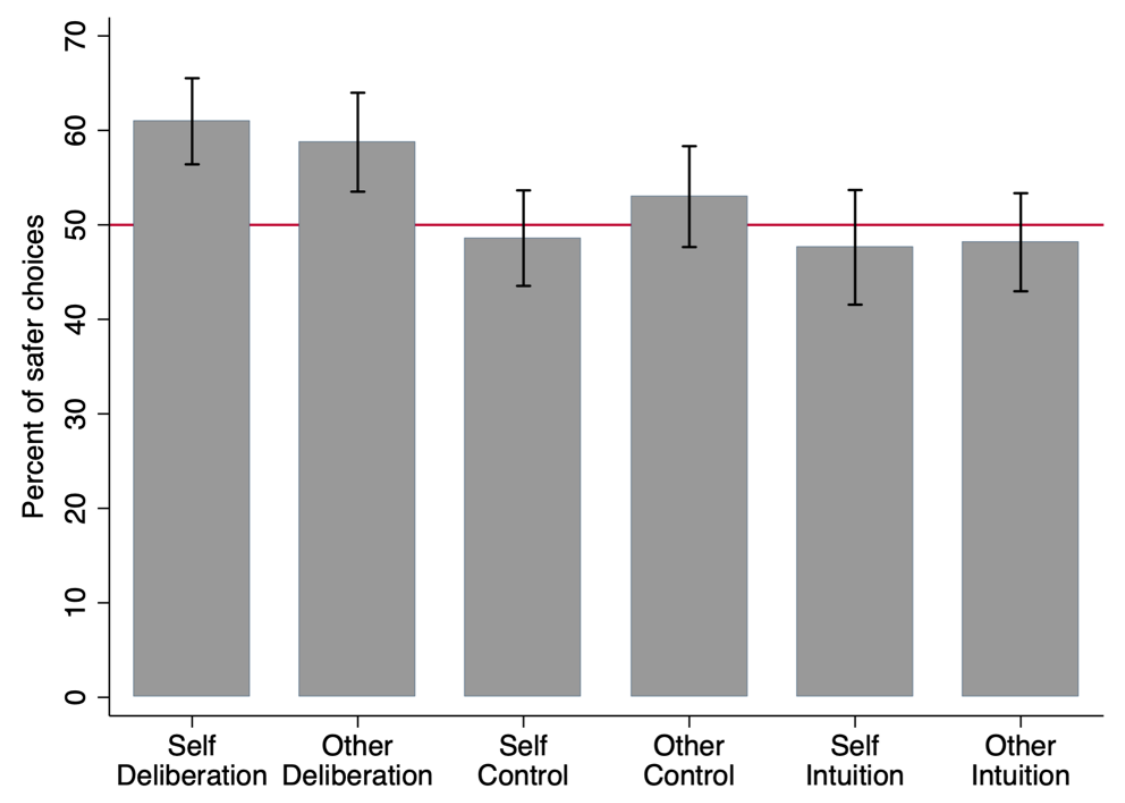

\section{Robustness analysis}

We test the robustness of our results by investigating whether the results from structural estimations change if we control for individuals' beliefs, social value orientation, or empathy score and interaction of these variables with dummy for Other. First of all, beliefs about other individual's risk preferences should affect one's choices for this person. Secondly, it can be argued that individuals who have stronger other-regarding preferences and care more about other people's well-being (Cooper and Kagel 2012) spend more cognitive resources on 
decisions for others. Further, as Faro and Rottenstreich (2006) argue, the hot-and-cold empathy gap can explain closer-to-risk-neutrality predictions of others' behavior. If individuals have troubles with taking the perspective of another individual (i.e., are less empathetic), it is difficult for them to predict others' emotional reactions that they experience when making decisions for oneself. In line with the risk-as-feelings hypothesis, this could result in more risk-neutral preferences when deciding for others (e.g., no fear of losses etc.) among less empathetic individuals, but not among highly empathetic individuals.

Beliefs were measured using incentivized investment task similar to Gneezy and Potters (1997). Subjects were endowed with 100 points and chose how many of them to invest. With $50 \%$ chance their investment was multiplied by factor 2.5 and with $50 \%$ they lost their investment. They made this choice twice: once for themselves and once for the same individual as in the lottery task. They were then asked to predict whether they invested more, less or the same amount for the other subject than the other subject invested for herself. Each point in this part of the experiment was worth $€ 0.01$. We used the slider task to measure social value orientation (Murphy et al. 2011) as this measure has been used in previous studies and is relatively short and easy to complete for subjects. SVO measures to what degree individuals care about others when deciding on the allocation of resources. For each of 15 items individuals had to choose their preferred allocation of resources between themselves and another anonymous person. Based on their choices, individuals are classified into one of four categories: altruistic, prosocial, individualist and competitive. Empirical data shows that individuals are rarely classified to one of the extreme categories (see for example Fiedler et al. 2013, Bieleke et al. 2017). In our sample, $46 \%$ of subjects are classified as prosocial and $54 \%$ are classified as individualistic. No subjects were classified as either altruistic or competitive. Each point in this part of the experiment was worth $€ 0.05$. To measure empathic concerns, we used a questionnaire developed by Davis (1980). Based on subject's responses we obtain a multidimensional empathy measure that consists of four scales: perspective taking (spontaneous adoption of other's point of view), fantasy (tendency to identify oneself with fictional characters), empathic concern (feeling of warmth and concern for others), and personal distress (feeling of anxiety when observing other's negative experience). We use median split to classify subjects as scoring high or low on each scale.

Table $\mathrm{C} 1$ presents results from structural estimations for CPT parameters. In each model we use dummies for treatments (with control being reference category) and Other as explanatory variables along with the control variables for beliefs/SVO/empathy and their interaction with dummy for Other. First and foremost, we find that our main findings (Result 1 
and Result 2) hold in all specifications when controlling for additional variables. Further findings are presented for each control variable:

Beliefs: Beliefs do not play a significant role in explaining any of the risk preference parameters, nor decision error. Individuals, who believe that the other person is more or less risk averse then themselves, make no different choices for others as for themselves.

Social value orientation: We find no differences in risk preferences between Self and Other when controlling for SVO type. However, we find that individuals classified as prosocial are less sensitive to outcomes, i.e., are more risk averse for gains and more risk seeking for losses when deciding for other than individualists deciding for others.

Empathy: We find no differences in risk preferences between Self and Other when controlling for empathy score, with the exception that individuals scoring high on personal distress have higher decision errors when deciding for others than for themselves.

Table C1 - The estimates of cumulative prospect theory parameters estimated using structural model with SVO type and empathy scores as explanatory variables.

\begin{tabular}{lcccc} 
Variables: & $\mu$ & $\lambda$ & $\gamma$ & $\sigma$ \\
\hline Beliefs & & & & \\
Other & 0.357 & 3.159 & 0.253 & $0.226^{*}$ \\
& $(0.246)$ & $(2.976)$ & $(0.216)$ & $(0.117)$ \\
Other is more risk averse & 0.120 & -0.470 & 0.131 & 0.063 \\
& $(0.145)$ & $(0.594)$ & $(0.251)$ & $(0.070)$ \\
Other is less risk averse & 0.188 & -0.210 & 0.094 & -0.028 \\
& $(0.116)$ & $(0.555)$ & $(0.174)$ & $(0.052)$ \\
Other \# Other is more risk averse & -0.391 & -1.256 & -0.222 & -0.101 \\
& $(0.297)$ & $(3.349)$ & $(0.291)$ & $(0.171)$ \\
Other \# Other is less risk averse & -0.351 & -3.396 & -0.205 & -0.169 \\
& $(0.277)$ & $(2.991)$ & $(0.242)$ & $(0.121)$ \\
Deliberation & 0.047 & $2.386^{* *}$ & -0.268 & -0.031 \\
& $(0.122)$ & $(1.071)$ & $(0.178)$ & $(0.044)$ \\
Intuition & 0.005 & 0.336 & 0.374 & 0.101 \\
& $(0.128)$ & $(0.408)$ & $(0.325)$ & $(0.076)$ \\
Constant & $0.758^{* * *}$ & 0.867 & $0.914^{* * *}$ & $0.298^{* * *}$ \\
& $(0.111)$ & $(0.544)$ & $(0.202)$ & $(0.051)$ \\
\hline SVO & & & & \\
Other & $0.286^{*}$ & 0.772 & 0.138 & $0.111^{* *}$ \\
& $(0.147)$ & $(0.766)$ & $(0.107)$ & $(0.052)$ \\
SVO: prosocial & -0.073 & 0.610 & -0.103 & -0.048 \\
& $(0.103)$ & $(0.383)$ & $(0.145)$ & $(0.045)$ \\
Other \# SVO: prosocial & $-0.396^{* *}$ & -0.090 & -0.052 & -0.008 \\
& $(0.174)$ & $(1.122)$ & $(0.158)$ & $(0.077)$ \\
Deliberation & -0.026 & $1.895^{* *}$ & $-0.372^{* *}$ & -0.073 \\
& $(0.109)$ & $(0.821)$ & $(0.181)$ & $(0.047)$ \\
Intuition & -0.015 & 0.147 & 0.244 & 0.082 \\
& $(0.135)$ & $(0.430)$ & $(0.331)$ & $(0.078)$ \\
Constant & $0.938^{* * *}$ & $0.381^{*}$ & $1.111^{* * *}$ & $0.345^{* * *}$ \\
& $(0.097)$ & $(0.204)$ & $(0.204)$ & $(0.049)$ \\
\hline
\end{tabular}




\begin{tabular}{|c|c|c|c|c|}
\hline & $\mu$ & $\lambda$ & $\gamma$ & $\sigma$ \\
\hline \multicolumn{5}{|l|}{ Empathy: perspective taking } \\
\hline Other & -0.004 & 0.471 & 0.129 & $0.126^{* *}$ \\
\hline \multirow{2}{*}{ Empathy: above-median } & $\begin{array}{c}(0.091) \\
0.172\end{array}$ & $\begin{array}{l}(0.758) \\
-0.253\end{array}$ & $\begin{array}{c}(0.105) \\
0.132\end{array}$ & $\begin{array}{c}(0.051) \\
0.033\end{array}$ \\
\hline & $(0.121)$ & $(0.343)$ & $(0.189)$ & $(0.058)$ \\
\hline \multirow[t]{2}{*}{ Other \# Empathy: above-median } & 0.239 & 0.822 & -0.043 & -0.062 \\
\hline & $(0.201)$ & $(1.240)$ & $(0.175)$ & $(0.082)$ \\
\hline \multirow[t]{2}{*}{ Deliberation } & 0.057 & $1.886 * *$ & $-0.291^{*}$ & -0.042 \\
\hline & $(0.113)$ & $(0.854)$ & $(0.173)$ & $(0.052)$ \\
\hline \multirow[t]{2}{*}{ Intuition } & 0.021 & 0.284 & 0.377 & 0.114 \\
\hline & $(0.130)$ & $(0.426)$ & $(0.345)$ & $(0.079)$ \\
\hline \multirow[t]{2}{*}{ Constant } & $0.806 * * *$ & $0.746 * *$ & $0.960 * * *$ & $0.294 * * *$ \\
\hline & $(0.089)$ & $(0.325)$ & $(0.162)$ & $(0.052)$ \\
\hline \multicolumn{5}{|l|}{ Empathy: fantasy } \\
\hline \multirow[t]{2}{*}{ Other } & 0.142 & 0.770 & 0.162 & $0.145 * * *$ \\
\hline & $(0.122)$ & $(0.619)$ & $(0.147)$ & $(0.053)$ \\
\hline \multirow[t]{2}{*}{ Empathy: above-median } & -0.052 & 0.642 & -0.220 & 0.001 \\
\hline & $(0.106)$ & $(0.435)$ & $(0.143)$ & $(0.043)$ \\
\hline \multirow[t]{2}{*}{ Other \# Empathy: above-median } & -0.091 & 0.131 & -0.033 & -0.064 \\
\hline & $(0.171)$ & $(1.351)$ & $(0.180)$ & $(0.081)$ \\
\hline \multirow[t]{2}{*}{ Deliberation } & 0.045 & $1.574^{*}$ & -0.280 & -0.047 \\
\hline & $(0.123)$ & $(0.818)$ & $(0.179)$ & $(0.050)$ \\
\hline \multirow[t]{2}{*}{ Intuition } & 0.006 & 0.153 & 0.348 & 0.084 \\
\hline & $(0.127)$ & $(0.358)$ & $(0.284)$ & $(0.066)$ \\
\hline \multirow[t]{2}{*}{ Constant } & $0.889 * * *$ & $0.464 * *$ & $1.089 * * *$ & $0.308 * * *$ \\
\hline & $(0.080)$ & $(0.217)$ & $(0.165)$ & $(0.040)$ \\
\hline \multicolumn{5}{|l|}{ Empathy: empathic concern } \\
\hline \multirow[t]{2}{*}{ Other } & 0.093 & 0.973 & 0.142 & $0.137 * * *$ \\
\hline & $(0.109)$ & $(0.744)$ & $(0.103)$ & $(0.048)$ \\
\hline \multirow[t]{2}{*}{ Empathy: above-median } & 0.029 & -0.161 & -0.071 & 0.070 \\
\hline & $(0.114)$ & $(0.434)$ & $(0.148)$ & $(0.054)$ \\
\hline \multirow[t]{2}{*}{ Other \# Empathy: above-median } & -0.024 & -0.310 & -0.051 & -0.090 \\
\hline & $(0.180)$ & $(1.145)$ & $(0.166)$ & $(0.085)$ \\
\hline \multirow[t]{2}{*}{ Deliberation } & 0.013 & $1.782 * *$ & $-0.315^{*}$ & -0.064 \\
\hline & $(0.118)$ & $(0.849)$ & $(0.181)$ & $(0.046)$ \\
\hline \multirow[t]{2}{*}{ Intuition } & 0.005 & 0.305 & 0.365 & 0.087 \\
\hline & $(0.129)$ & $(0.451)$ & $(0.313)$ & $(0.070)$ \\
\hline Constant & $0.875 * * *$ & $0.651 * *$ & $1.039 * * *$ & $0.299 * * *$ \\
\hline & $(0.095)$ & $(0.310)$ & $(0.178)$ & $(0.038)$ \\
\hline Empathy: personal distress & & & & \\
\hline Other & 0.121 & 1.051 & 0.134 & $0.089^{*}$ \\
\hline & $(0.127)$ & $(0.775)$ & $(0.122)$ & $(0.053)$ \\
\hline Empathy: above-median & -0.100 & -0.043 & -0.161 & -0.062 \\
\hline & $(0.108)$ & $(0.358)$ & $(0.144)$ & $(0.046)$ \\
\hline Other \# Empathy: above-median & -0.090 & -0.629 & -0.058 & 0.047 \\
\hline & $(0.168)$ & $(1.342)$ & $(0.163)$ & $(0.081)$ \\
\hline Deliberation & 0.002 & $1.764 * *$ & -0.285 & -0.069 \\
\hline & $(0.123)$ & $(0.832)$ & $(0.181)$ & $(0.056)$ \\
\hline Intuition & -0.006 & 0.403 & 0.432 & 0.092 \\
\hline & $(0.134)$ & $(0.466)$ & $(0.322)$ & $(0.081)$ \\
\hline Constant & $0.934 * * *$ & $0.587^{*}$ & $1.056 * * *$ & $0.349 * * *$ \\
\hline & $(0.105)$ & $(0.326)$ & $(0.173)$ & $(0.058)$ \\
\hline Observations & 11,498 & 11,498 & 11,498 & 11,498 \\
\hline
\end{tabular}


Note: Constant represents the parameter value for an individual who either believes that other person has the same risk preferences as herself, or classified as individualist (SVO), or with below-median empathy score (on a given scale) in control treatment making choices for herself. Standard errors clustered at the subject level in parentheses. $* * * \mathrm{p}<0.01, * * \mathrm{p}<0.05, * \mathrm{p}<0.1$

\section{Tables}

Table D1—Full sample and subsample characteristics

\begin{tabular}{l|cc} 
Variable & $\begin{array}{c}\text { Full sample } \\
(\mathrm{n}=128)\end{array}$ & $\begin{array}{c}\text { Eye-tracking } \\
(\mathrm{n}=94)\end{array}$ \\
\hline \hline Treatment & 0.33 & 0.34 \\
Control & 0.34 & 0.34 \\
Deliberation & 0.34 & 0.32 \\
Intuition & 21.8 & 22.0 \\
Age & 0.62 & 0.55 \\
Female & 0.31 & 0.32 \\
Employed & 327.5 & 346.5 \\
Monthly budget & & \\
(€) & & \\
SVO & 0.46 & 0.45 \\
Prosocial & 0.54 & 0.55 \\
Individualist & & \\
Beliefs & 0.28 & 0.24 \\
Invested more & 0.29 & 0.29 \\
Invested same & 0.43 & 0.47 \\
Invested less & & \\
\hline \hline
\end{tabular}

Notes: All values except for Age denote proportions in the respective subsample

Table D2 - Robustness of the information processing analysis with respect to the definition of a fixation (i.e., changing the dispersion and length thresholds)

\begin{tabular}{|c|c|c|c|c|c|c|c|}
\hline Measure & Self & Other & $\mathrm{p}(\mathrm{S}$ vs $\mathrm{O})$ & Deliberation & Control & Intuition & $\mathrm{p}(\mathrm{I}$ vs D) \\
\hline \multicolumn{8}{|c|}{ Dispersion: 30 pixel, duration: $\min 117 \mathrm{~ms}$} \\
\hline $\begin{array}{l}\text { Number of } \\
\text { fixations } \\
\mathrm{N}=94\end{array}$ & 27.84 & 22.33 & 0.014 & 28.16 & 26.99 & 19.23 & $<0.001$ \\
\hline $\begin{array}{l}\text { Proportion AOI } \\
\mathrm{N}=94\end{array}$ & $85.69 \%$ & $77.57 \%$ & 0.038 & $87.22 \%$ & $81.57 \%$ & $74.92 \%$ & $<0.001$ \\
\hline $\begin{array}{l}\text { Fixation } \\
\text { Duration (msec) } \\
\mathrm{N}=94\end{array}$ & 295.84 & 285.84 & 0.321 & 303.41 & 289.35 & 278.04 & 0.049 \\
\hline \multicolumn{8}{|c|}{ Dispersion: 30 pixel, duration: $\min 133 \mathrm{~ms}$} \\
\hline $\begin{array}{l}\text { Number of } \\
\text { fixations } \\
\mathrm{N}=94\end{array}$ & 26.43 & 21.11 & 0.016 & 26.70 & 25.55 & 18.20 & $<0.001$ \\
\hline $\begin{array}{l}\text { Proportion AOI } \\
\mathrm{N}=94\end{array}$ & $84.73 \%$ & $76.38 \%$ & 0.038 & $86.30 \%$ & $80.48 \%$ & $73.68 \%$ & $<0.001$ \\
\hline $\begin{array}{l}\text { Fixation } \\
\text { Duration (msec) } \\
\mathrm{N}=94\end{array}$ & 304.78 & 295.67 & 0.306 & 312.94 & 298.62 & 287.48 & 0.037 \\
\hline
\end{tabular}




\begin{tabular}{|c|c|c|c|c|c|c|c|}
\hline \multicolumn{8}{|c|}{ Dispersion: 30 pixel, duration: $\min 150 \mathrm{~ms}$} \\
\hline $\begin{array}{l}\text { Number of } \\
\text { fixations } \\
N=94\end{array}$ & 25.03 & 19.89 & 0.018 & 25.27 & 24.11 & 17.19 & $<0.001$ \\
\hline $\begin{array}{l}\text { Proportion AOI } \\
\mathrm{N}=94\end{array}$ & $83.56 \%$ & $74.87 \%$ & $\mathbf{0 . 0 3 3}$ & $85.11 \%$ & $79.11 \%$ & $72.16 \%$ & $<0.001$ \\
\hline $\begin{array}{l}\text { Fixation } \\
\text { Duration (msec) } \\
\mathrm{N}=94\end{array}$ & 313.78 & 305.42 & 0.296 & 322.59 & 308.07 & 296.54 & 0.024 \\
\hline \multicolumn{8}{|c|}{ Dispersion: 40 pixel, duration: $\min 100 \mathrm{~ms}$} \\
\hline $\begin{array}{l}\text { Number of } \\
\text { fixations } \\
N=94\end{array}$ & 29.33 & 23.90 & 0.016 & 29.75 & 28.80 & 20.41 & $<0.001$ \\
\hline $\begin{array}{l}\text { Proportion AOI } \\
N=94\end{array}$ & $86.71 \%$ & $79.32 \%$ & $\mathbf{0 . 0 3 3}$ & $88.46 \%$ & $82.89 \%$ & $76.59 \%$ & $<0.001$ \\
\hline $\begin{array}{l}\text { Fixation } \\
\text { Duration (msec) } \\
\mathrm{N}=94\end{array}$ & 298.75 & 286.38 & 0.265 & 305.21 & 290.52 & 280.02 & 0.078 \\
\hline \multicolumn{8}{|c|}{ Dispersion: 40 pixel, duration: $\min 117 \mathrm{~ms}$} \\
\hline $\begin{array}{l}\text { Number of } \\
\text { fixations } \\
N=94\end{array}$ & 27.78 & 22.41 & 0.014 & 28.07 & 27.11 & 19.24 & $<0.001$ \\
\hline $\begin{array}{l}\text { Proportion AOI } \\
\mathrm{N}=94\end{array}$ & $86.14 \%$ & $78.42 \%$ & 0.042 & $87.80 \%$ & $82.18 \%$ & $75.71 \%$ & $<0.001$ \\
\hline $\begin{array}{l}\text { Fixation } \\
\text { Duration (msec) } \\
\mathrm{N}=94\end{array}$ & 308.59 & 297.28 & 0.234 & 316.46 & 300.59 & 289.89 & 0.046 \\
\hline \multicolumn{8}{|c|}{ Dispersion: 40 pixel, duration: $\min 133 \mathrm{~ms}$} \\
\hline $\begin{array}{l}\text { Number of } \\
\text { fixations } \\
\mathrm{N}=94\end{array}$ & 26.69 & 21.43 & 0.015 & 26.96 & 25.96 & 18.42 & $<0.001$ \\
\hline $\begin{array}{l}\text { Proportion AOI } \\
\mathrm{N}=94\end{array}$ & $85.52 \%$ & $77.38 \%$ & 0.035 & $87.15 \%$ & $81.28 \%$ & $74.74 \%$ & $<0.001$ \\
\hline $\begin{array}{l}\text { Fixation } \\
\text { Duration (msec) } \\
\mathrm{N}=94\end{array}$ & 315.74 & 305.71 & 0.253 & 324.14 & 308.34 & 297.95 & 0.036 \\
\hline \multicolumn{8}{|c|}{ Dispersion: 40 pixel, duration: $\min 150 \mathrm{~ms}$} \\
\hline $\begin{array}{l}\text { Number of } \\
\text { fixations } \\
N=94\end{array}$ & 25.58 & 20.42 & 0.016 & 25.80 & 24.79 & 17.59 & $<0.001$ \\
\hline $\begin{array}{l}\text { Proportion AOI } \\
\mathrm{N}=94\end{array}$ & $84.57 \%$ & $76.12 \%$ & 0.029 & $86.12 \%$ & $80.27 \%$ & $73.41 \%$ & $<0.001$ \\
\hline $\begin{array}{l}\text { Fixation } \\
\text { Duration (msec) } \\
\mathrm{N}=94\end{array}$ & 323.24 & 314.20 & 0.275 & 332.17 & 316.54 & 305.79 & 0.027 \\
\hline
\end{tabular}




\section{E. Figures}

Figure E1: Screen shot from one of the lottery stages during the experiment.

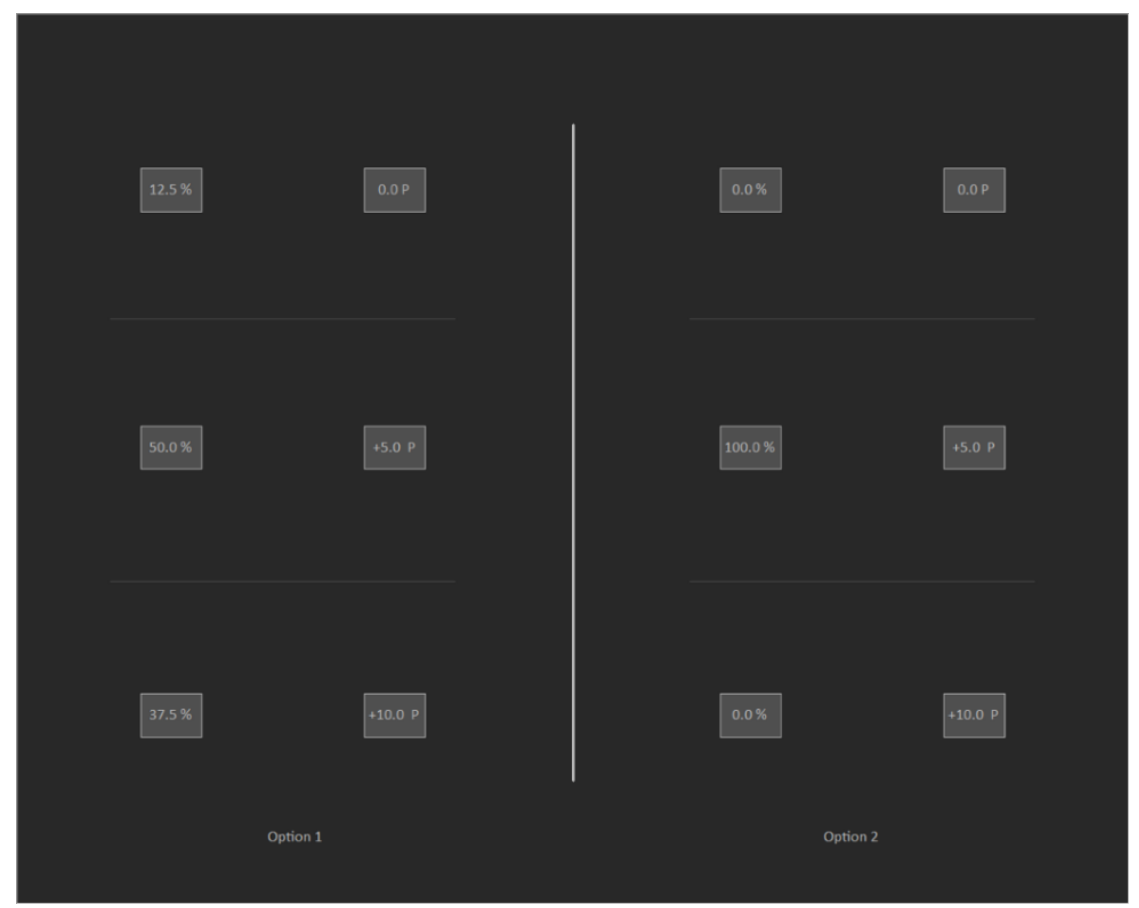

Figure E2: Decision time (seconds) by treatment for Self and Other ( $\mathrm{n}=128,2$ blocks per person). Error bars indicate the $95 \%$ confidence interval of the means accounting for the clustering at the individual level.

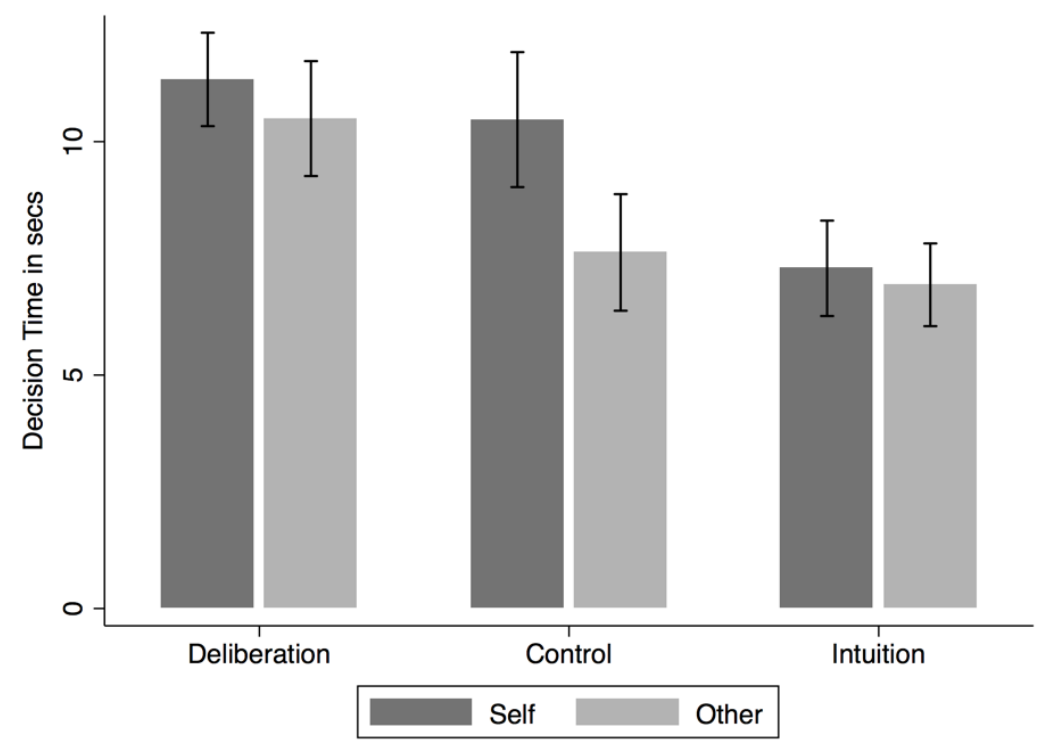


Figure E3: Decision time (seconds) by treatment for Self and Other ( $\mathrm{n}=128$, only first block per person). Error bars indicate the $95 \%$ confidence interval of the means accounting for the clustering at the individual level.

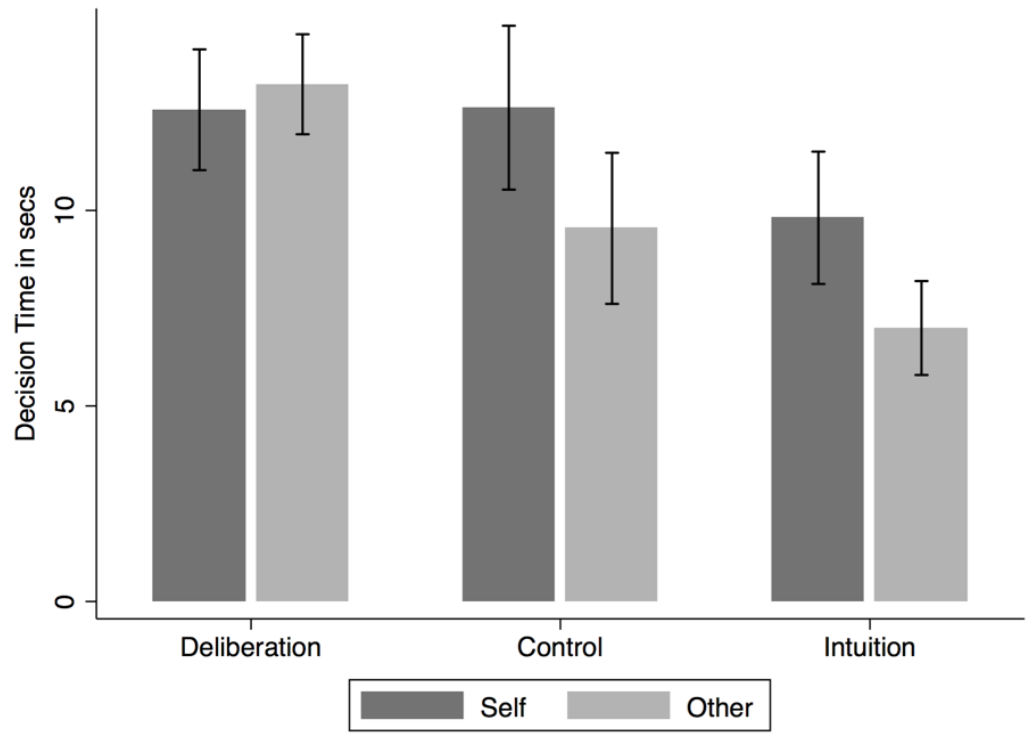

Figure E4: Number of fixations per stage by treatment for Self and Other ( $\mathrm{n}=94$, only first block per person). Error bars indicate the $95 \%$ confidence interval of the means accounting for the clustering at the individual level.

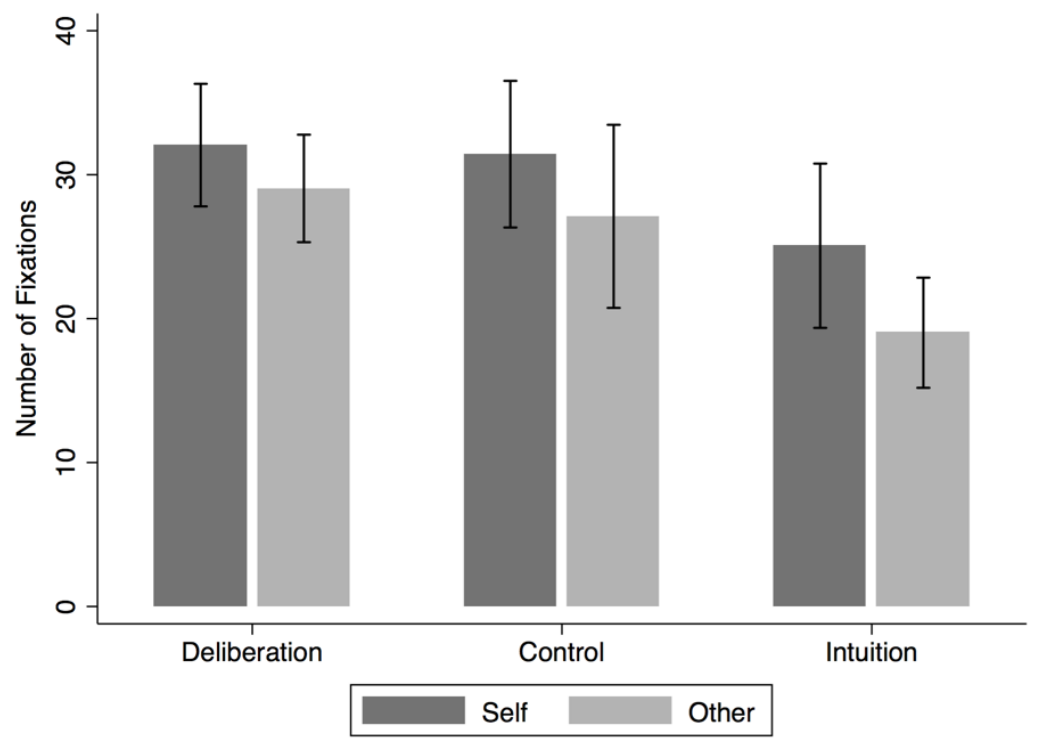


Figure E5: Proportion of inspected AOIs per stage by treatment for Self and Other ( $\mathrm{n}=94$, only first block per person). Error bars indicate the $95 \%$ confidence interval of the means accounting for the clustering at the individual level.

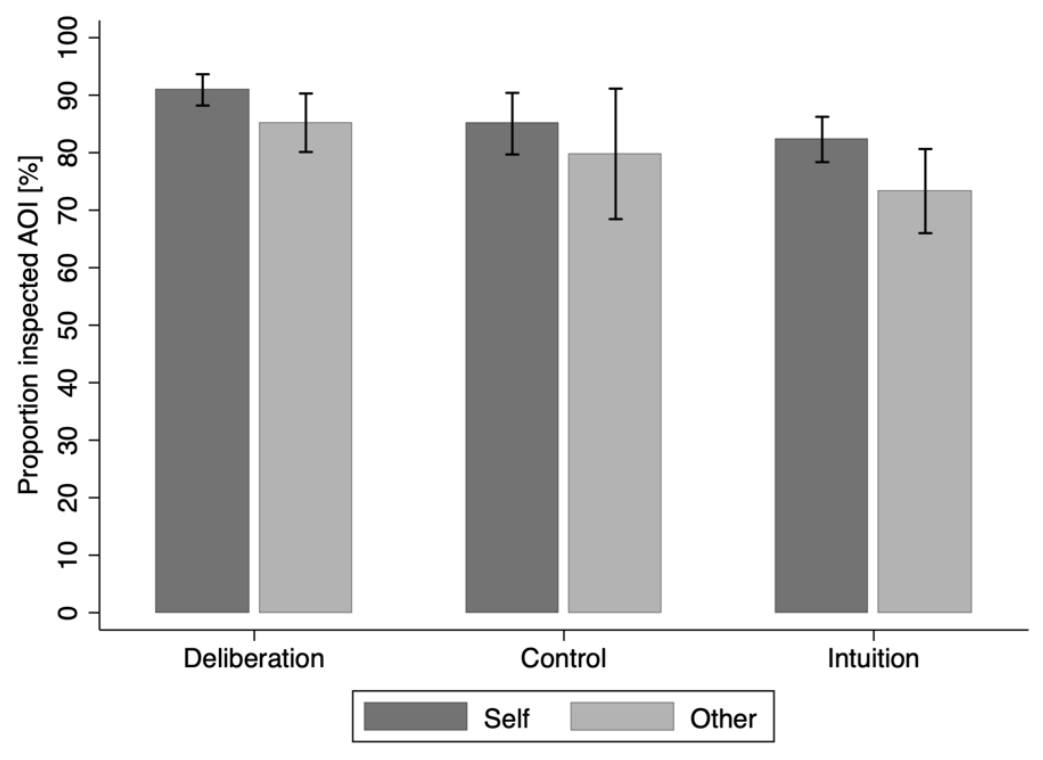

Figure E6: Fixation duration (milliseconds) by treatment for Self and Other ( $\mathrm{n}=94$, only first block per person). Error bars indicate the $95 \%$ confidence interval of the means accounting for the clustering at the individual level.

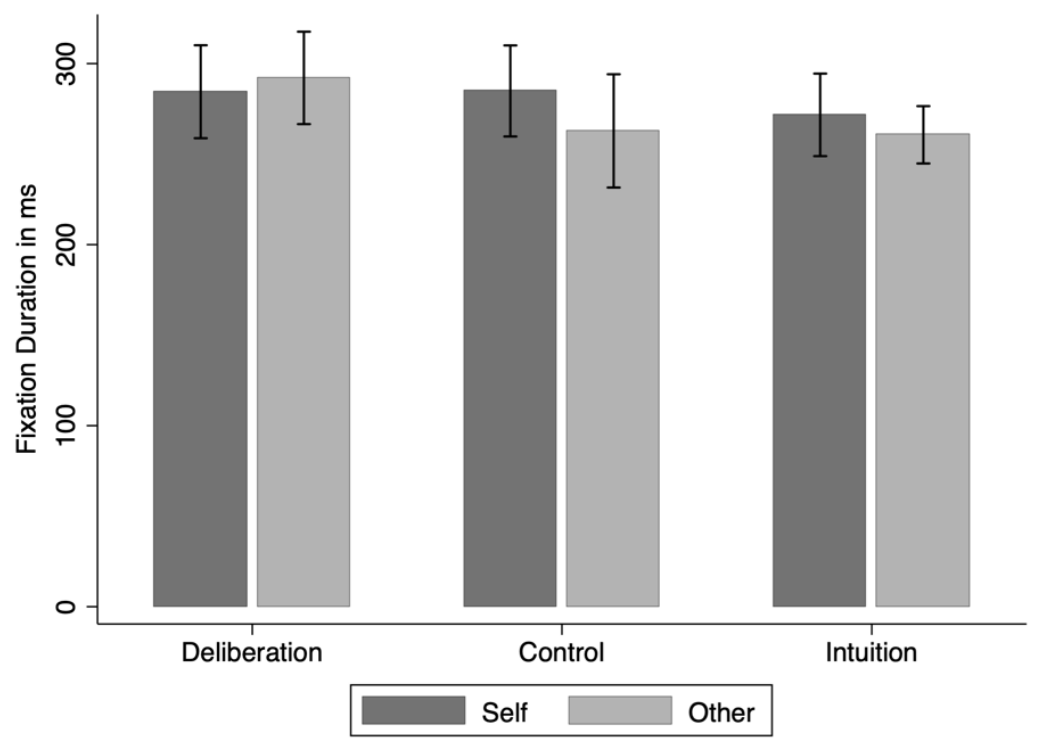




\section{F. Instructions Other}

In this part, you do not decide for yourself but on behalf of another participant. This is not the same person as in the task in Part I [note: SVO task]. This person is not the person that decides on your behalf. Your decisions in this part are only payoff relevant for the other person.

\section{G. Instructions Intuition}

In this part, we are especially interested in the influence of intuitive acting on decisions. Avoid thinking for too long. Instead, attend to your first impression and listen to your guts.

In order to make better decisions, it helps to listen to your guts. According to research, making if-then plans helps achieving this. Please make the following if-then plan:

\section{If I start contemplating,}

then I tell myself: listen to your guts!

Please envision and memorize this plan.

In order to so, please read out the plan three times in thought.

As soon as you have memorized this plan, you can go the next page.

Please write down the if-then plan once:

If

then I tell myself:

\section{End of the exercise}

You have finished the exercise. Please type in the following 4 letters s-k-y-m (in this order) and click on "Weiter" to let us know that you are done with the exercise.

Please consider that the experiment will not continue until the 5 minute processing time is over. 


\section{H. Instructions Deliberation}

In this part, we are especially interested in the influence of carefully deliberating on decisions. Avoid acting prematurely. Instead, carefully balance the options and use your brain when deciding.

In order to make better decisions, it helps to use your brain. According to research, making ifthen plans helps achieving this. Please make the following if-then plan:

\section{If I start acting prematurely,}

then I tell myself: use your brain!

Please envision and memorize this plan.

In order to so, please read out the plan three times in thought.

As soon as you have memorized this plan, you can go the next page.

Please write down the if-then plan once:

If

then I tell myself:

\section{End of the exercise}

You have finished the exercise. Please type in the following 4 letters $\mathbf{s}-\mathbf{k}-\mathbf{y}-\mathbf{m}$ (in this order) and click on "Weiter" to let us know that you are done with the exercise.

Please consider that the experiment will not continue until the 5 minute processing time is over. 


\section{Instructions Control}

Before part 2 starts, please copy the following forms onto the empty sheet.
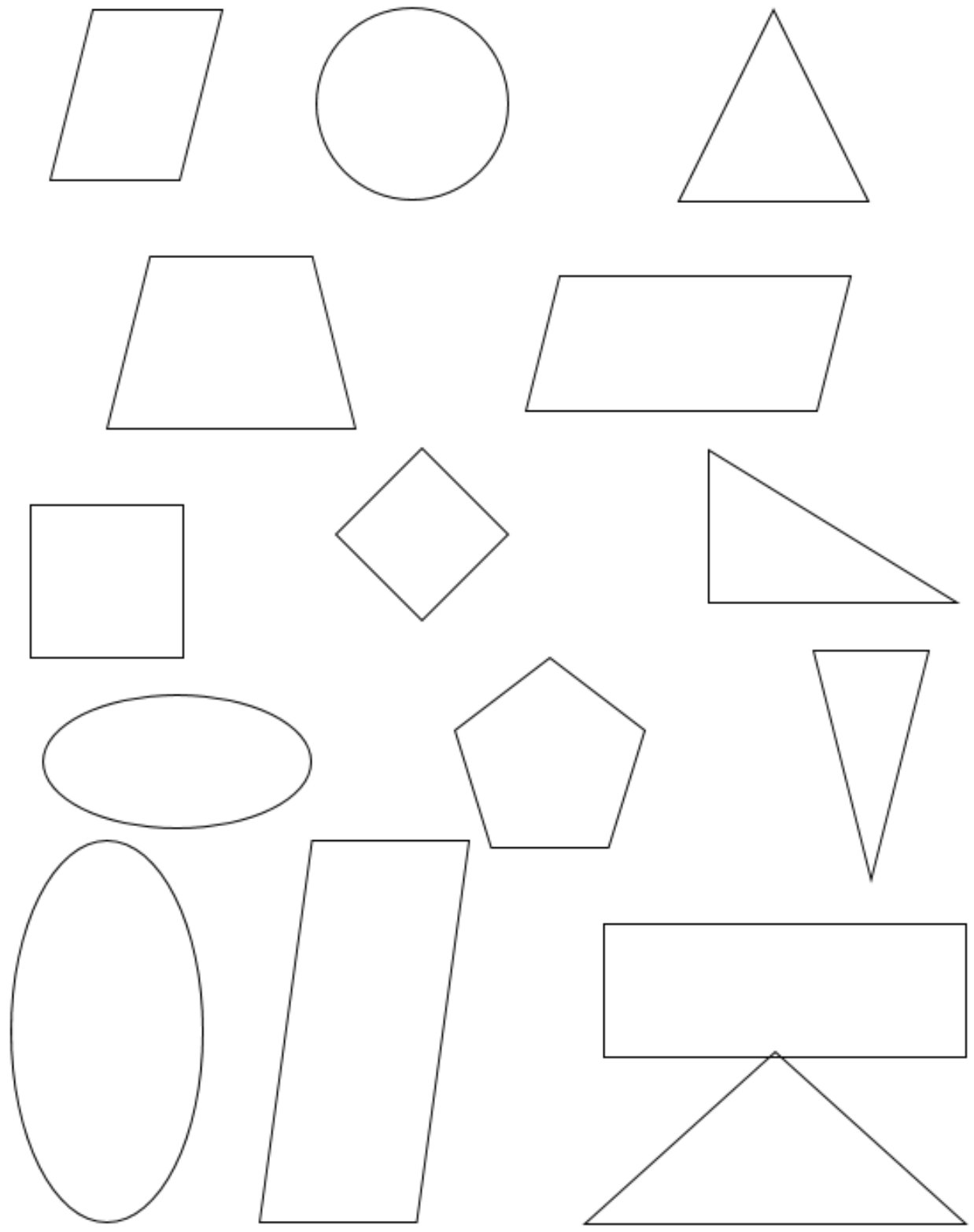
How comfortable was the chin rest so far?

Do you have any recommendation how future eye-tracking studies can be conducted in a more comfortable way?

\section{End of the exercise}

You have finished the exercise. Please type in the following 4 letters s-k-y-m (in this order) and click on "Weiter" to let us know that you are done with the exercise.

Please consider that the experiment will not continue until the 5 minute processing time is over. 


\section{J. Instructions Lottery Task}

\section{Part 2}

This part consists of 45 decisions. These 45 decisions are split into 3 blocks of 15 choices. In each decision, you have to choose between 2 options. The option differ in the value of the points and the probability with which these points are achieved. The probability is shown in the left boxes for both options. The points are shown in the right boxes for both options. For each option, there are 3 points-probability pairs. These point-probability pairs are displayed in the example with \%-P-Paar. The marking (ellipse and legend) will not be present in the actual decisions.

In the example below, option 1 yields:

10 points with a probability of $25 \%$ (first $\%$-P-Paar), 8 points with a probability of $50 \%$ (second $\%$-P-Paar), and 4 points with a probability of $25 \%$ (third \%-P-Paar).

In the example below, option 2 yields:

15 points with a probability of $75 \%$ (first \%-P-Paar), 6 points with a probability of $0 \%$ (second $\%$-P-Paar), and 5 points with a probability of $25 \%$ (third \%-P-Paar).

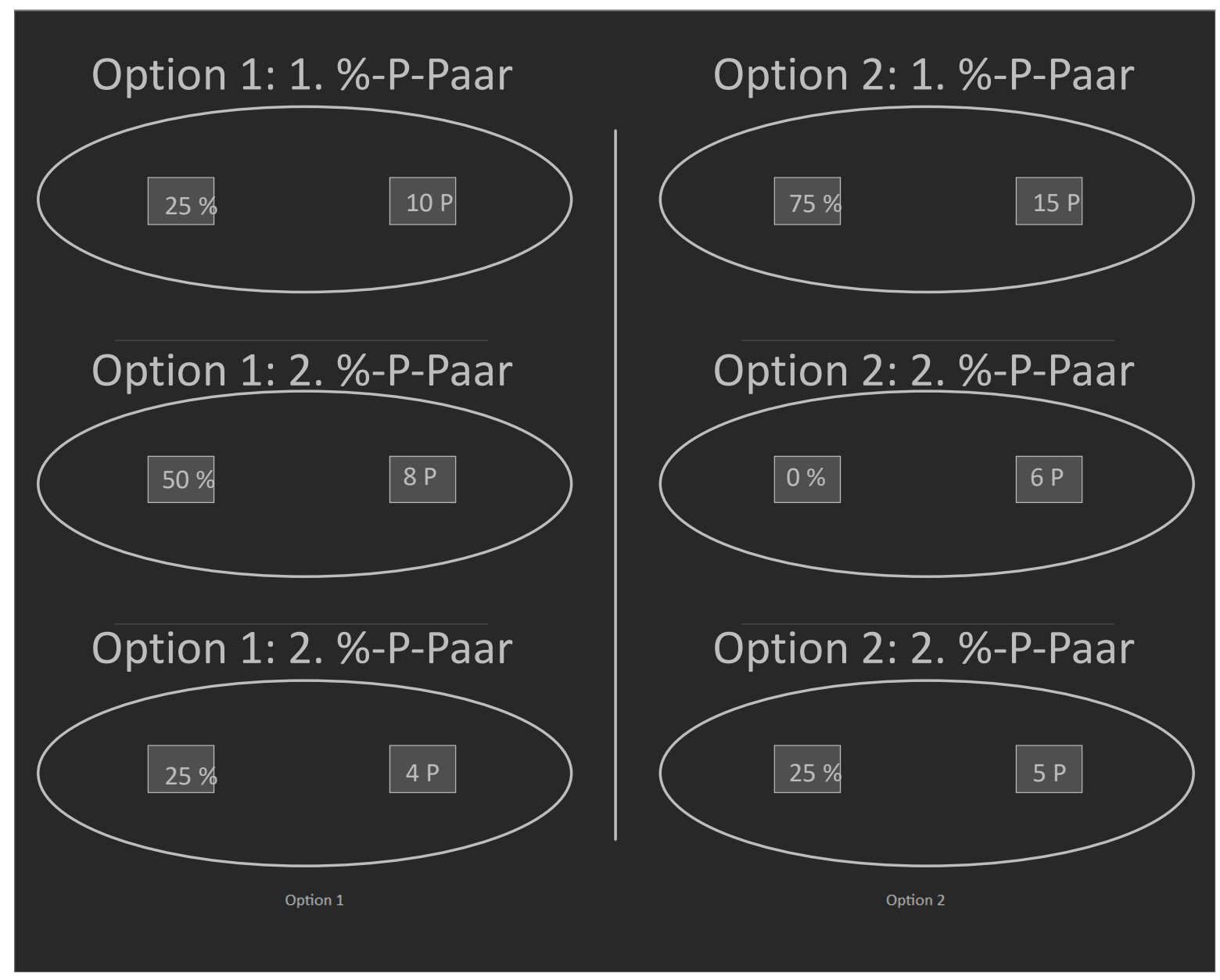


In order to decide between option 1 and option 2, you either press

y-key for option $1 \quad$ or m-key for option 2.

Please position your fingers on the respective keys. You will also receive a reminder about this later on.

Before each decision, you will see a cross in the middle of screen. As soon as this cross disappears, the two options appear and you can make your choice.

In part 2, there are 3 different types:

Type 1: You can only achieve positive points or 0 points. In these cases, you will not receive any additional points.

Type 2: You can achieve positive, 0 points, as well as negative points. In these cases, you will receive $\underline{8}$ additional points.

Type 3: You can only achieve negative points or 0 points. In these cases, you will receive 15 additional points.

Both options always have points of the same value, e.g.:

If options 1 yields 4,0 , and -5 points, then option 2 will also yield a positive a negative and 0 points. In this case, you will receive 8 additional points.

If options 1 yields $-10,-5$, and 0 points, then option 2 will also yield only negative and 0 points. In this case, you will receive 15 additional points.

As a reminder: In the example from the picture above, you would not receive any additional points.

Only one decision from part 2 will be paid out. At the end of the experiment, someone will determine the decision by rolling a die. As the decisions differ, the realization of the option (which probability) will also be determined using a die. Points gained in this experiment are conversed into Euro using:

1 Point $=0.5$ Euro.

Please answer all control questions appearing on screen. If you have questions, please raise your hand. These answers do not influence your payment. 